\title{
Cognitive and familial risk evidence converged: A data-driven identification of distinct and homogeneous subtypes within the heterogeneous sample of reading disabled children
}

Citation for published version (APA):

Willems, G., Jansma, B., Blomert, L., \& Vaessen, A. (2016). Cognitive and familial risk evidence converged: A data-driven identification of distinct and homogeneous subtypes within the heterogeneous sample of reading disabled children. Research in Developmental Disabilities, 53-54, 213-231. https://doi.org/10.1016/j.ridd.2015.12.018

Document status and date:

Published: 01/01/2016

DOI:

10.1016/j.ridd.2015.12.018

Document Version:

Publisher's PDF, also known as Version of record

\section{Document license:}

Taverne

\section{Please check the document version of this publication:}

- A submitted manuscript is the version of the article upon submission and before peer-review. There can be important differences between the submitted version and the official published version of record. People interested in the research are advised to contact the author for the final version of the publication, or visit the $\mathrm{DOI}$ to the publisher's website.

- The final author version and the galley proof are versions of the publication after peer review.

- The final published version features the final layout of the paper including the volume, issue and page numbers.

Link to publication

\footnotetext{
General rights rights.

- You may freely distribute the URL identifying the publication in the public portal. please follow below link for the End User Agreement:

www.umlib.nl/taverne-license

Take down policy

If you believe that this document breaches copyright please contact us at:

repository@maastrichtuniversity.nl

providing details and we will investigate your claim.
}

Copyright and moral rights for the publications made accessible in the public portal are retained by the authors and/or other copyright owners and it is a condition of accessing publications that users recognise and abide by the legal requirements associated with these

- Users may download and print one copy of any publication from the public portal for the purpose of private study or research.

- You may not further distribute the material or use it for any profit-making activity or commercial gain

If the publication is distributed under the terms of Article $25 \mathrm{fa}$ of the Dutch Copyright Act, indicated by the "Taverne" license above,

Download date: 26 Apr. 2023 


\title{
Cognitive and familial risk evidence converged: A data-driven identification of distinct and homogeneous subtypes within the heterogeneous sample of reading disabled children
}

\author{
Gonny Willems *, Bernadette Jansma, Leo Blomert ${ }^{1}$, Anniek Vaessen \\ Department of Cognitive Neuroscience, Faculty of Psychology \& Neuroscience, Maastricht University, and Maastricht Brain Imaging Centre \\ (M-BIC), P.O. Box 616, 6200 MD Maastricht, The Netherlands
}

\section{A R T I C L E I N F O}

\section{Article history:}

Received 10 April 2015

Received in revised form 1 November 2015

Accepted 5 December 2015

Available online 27 February 2016

\section{Keywords:}

Subtypes of reading disability

Data-driven clustering

Cognitive profiling

Familial risk and environmental risk factors

Dyslexia deficits

\begin{abstract}
A B S T R A C T
The evident degree of heterogeneity observed in reading disabled children has puzzled reading researchers for decades. Recent advances in the genetic underpinnings of reading disability have indicated that the heritable, familial risk for dyslexia is a major risk factor. The present data-driven, classification attempt aims to revisit the possibility of identifying distinct cognitive deficit profiles in a large sample of second to fourth grade reading disabled children. In this sample, we investigated whether genetic and environmental risk factors are able to distinguish between poor reader subtypes. In this profile, we included readingrelated measures of phonemic awareness, letter-speech sound processing and rapid naming, known as candidate vulnerability markers associated with dyslexia and familial risk for dyslexia, as well as general cognitive abilities (non-verbal IQ and vocabulary). Clustering was based on a 200 multi-start $K$-means approach. Results revealed four emerging subtypes of which the first subtype showed no cognitive deficits underlying their poor reading skills (Reading-only impaired poor readers). The other three subtypes shared a core phonological deficit (PA) with a variable and discriminative expression across the other underlying vulnerability markers. More specific, type 2 showed low to poor performance across all reading-related and general cognitive abilities (general poor readers), type 3 showed a specific letter-speech sound mapping deficit next to a PA deficit (PA-LS specific poor readers) and type 4 showed a specific rapid naming deficit complementing their phonological weakness (PA-RAN specific poor readers). The first three poor reader profiles were more characterized by variable environmental risk factor, while the fourth, $P A-R A N$ poor reader subtype showed a significantly strong familial risk for dyslexia. Overall, when we zoom in on the heterogeneous phenomenon of reading disability, unique and distinct cognitive subtypes can be identified, distinguishing between those poor readers more influences by the role of genes and those more influenced by environmental risk factors. Taking into account this diversity of distinct cognitive subtypes, instead of looking at the reading disabled sample as a whole, will help tailor future diagnostic and intervention efforts more specifically to the needs of children with such a specific deficit and risk pattern, as well as providing a more promising way forward for genetic studies of dyslexia.
\end{abstract}

(c) 2016 Elsevier Ltd. All rights reserved.

\footnotetext{
Abbreviations: PA, phonological/phonemic awareness; LS, letter-speech sound processing; RAN, rapid automatized naming.

* Corresponding author.

E-mail addresses: g.willems@maastrichtuniversity.nl (G. Willems), b.jansma@maastrichtuniversity.nl (B. Jansma), a.vaessen@rid.nl (A. Vaessen).

${ }^{1}$ Deceased.
} 


\section{Introduction}

While most children become fluent readers without much effort within a few years of reading instruction, a considerable number of children experience great difficulties in acquiring adequate literacy skills. Developmental dyslexia, a specific learning disability resulting in reading and spelling impairments despite normal intelligence and proper educational instruction (Lyon, Shaywitz, \& Shaywitz, 2003; Peterson \& Pennington, 2012), is only one possible cause of the reading failure experienced by the heterogeneous group of poor readers (Heim \& Grande, 2012; Menghini et al., 2010; Pennington et al., 2012; van Bergen, van der Leij, \& de Jong, 2014). Consequently, there have been numerous attempts to classify distinct and coherent cognitive profiles of reading failure. Traditionally, classification studies have divided poor readers into pre-defined categories, based on existing theoretical insights regarding the etiology of the different reading profiles, such as the 'IQreading performance discrepancy' hypothesis (Rutter \& Yule, 1975), the 'phonological-core variable-difference' model (Stanovich, 1988) or according to a specific word decoding deficit or a broader decoding-comprehension deficit, i.e., the 'simple view of reading' (Gough \& Tunmer, 1986). These earlier studies have significantly influenced the ongoing debate on what constitutes dyslexia and have at least supported the possibility to distinguish between a specific reading disabled, or dyslexic profile, and a more general poor, or garden-variety profile (Gough \& Tunmer, 1986; Rutter \& Yule, 1975; Stanovich, 1988). In more recent years however, new developments in the genetic underpinnings of reading disability added greatly to the current definition of dyslexia as a specific learning disability with a neurobiological origin and strong genetic disposition to develop reading difficulties (Byrne et al., 2006; Castles, Datta, Gayan, \& Olson, 1999; Grigorenko, 2001; Pennington \& Olson, 2008; Williams \& O'Donovan, 2006). Reading problems experienced by dyslexic children are highly heritable and run in families (Pennington \& Olson, 2008). Approximately 40-65\% of children at familial risk are expected to develop dyslexia (Blomert \& Willems, 2010; Pennington \& Lefly, 2001; Pennington \& Olson, 2008; Scarborough, 1990), indicating that the chances to develop dyslexia, given a dyslexic parent or sibling, amount to at least 10 times the population prevalence (i.e., 4-5\%, Blomert, 2005). Although having a familial history of dyslexia is one of the strongest risk factors of the disorder (Thompson et al., 2015), it should not be considered as a pure genetic component (Plomin, Reiss, Hetherington, \& Howe, 1994; Rutter \& Silberg, 2002). Since at-risk children share both genes and home literacy environment with their close relatives, gene-environment interaction has been studied to understand reading deficits better. It has been shown that children with general impairments across various cognitive abilities are often more specially influenced by environmental risk factors and less by familial risk (Castles et al., 1999; Gayan \& Olson, 2001; Grigorenko, 2001; Rack \& Olson, 1993; Wadsworth, Olson, Pennington, \& DeFries, 2000). A neuroimaging study supported two subtypes demonstrating the existence of two distinct brain activation profiles characterizing a primarily genetic poor reader type and an environmentally influenced more generally impaired type (Shaywitz \& Shaywitz, 2005). One relevant question now is whether this environmental poor reader subtype can be differentiated from the poor reader subtype with a familial risk of dyslexia based on distinct, underlying cognitive deficit patterns. The present clustering study, for the first time, aims to investigate emerging cognitive subtypes of reading disability related to at-risk status based on history of dyslexia as well as environmental factors. We hypothesize that if the development of reading difficulties of a certain cognitive subtype of reading disability is influenced more strongly by a familial predisposition or alternatively more strongly by environmental risk factors, that this influence will also be reflected in their underlying cognitive deficit pattern. The possibility of identifying unique poor reading profiles will help tailor future diagnostic and intervention efforts more effectively than is currently possible.

Several important cognitive risk factors, or 'vulnerability markers', have been identified as important behavioral markers useful for the identification of reading disability. Traditional single deficit accounts of dyslexia point to weakness in phonological awareness (PA) as the core deficit in dyslexia (Adams, 1990; Goswami \& Bryant, 1990; Ramus, 2003; Snowling, 2000; Vellutino, Fletcher, Snowling, \& Scanlon, 2004). However, more recently a growing tendency emerged to view neurodevelopmental disorders like literacy impairment as the product of various interacting vulnerability markers with distinct, behavioral profiles as a result (Bishop, 2006, 2008; Pennington \& Olson, 2008; Snowling, 2008, 2012). Family studies of dyslexia confirm that there is indeed a spectrum of reading disorders (Snowling \& Hulme, 2012). Although a single PA deficit explanation of dyslexia is under discussion, it is undisputed that PA is a main characteristic of reading disability (e.g., Ramus et al., 2003; Sunseth \& Bowers, 2002). Reading disabled children at increased familial risk for dyslexia show significantly weaker PA skills than non-risk controls (e.g., Carroll, Mundy, \& Cunningham, 2014). In turn, both impaired and unimpaired at-risk children show PA problems (Puolakanaho et al., 2008; Snowling, Gallagher, \& Frith, 2003), resulting in a parametric increase of reading problems (i.e., healthy $<$ unimpaired at-risk $<$ impaired at-risk: Boets, Wouters, Van Wieringen, \& Ghesquiere, 2007; Elbro, Borstrøm, \& Petersen, 1998; Moll, Loff, \& Snowling, 2013; Pennington \& Lefly, 2001; Snowling et al., 2003). Although it was always assumed that PA plays a causal role in reading acquisition (Snowling, 2000; Vellutino et al., 2004; Wagner \& Torgesen, 1987), this has be opposed by others who indicated that a PA deficit develops in close relation with the developing reading deficit (Blomert \& Willems, 2010; Castles \& Coltheart, 2004; Castles, Wilson, \& Coltheart, 2011; Morais, Cary, Alegria, \& Bertelson, 1979; Perfetti, Beck, Bell, \& Hughes, 1987). Genetic studies also indicated that a PA deficit is associated with a genetic predisposition of dyslexia which, although often differing in severity, can be present in both affected and unaffected family members (Berninger et al., 2006; Snowling, 2008).

Another candidate vulnerability marker of dyslexia is the ability to rapidly name familiar visual symbols such as objects, letters or colors, known as Rapid automatized naming (RAN) (Berninger, Abbott, Billingsley, \& Nagy, 2001; Berninger et al., 2006; Bowers \& Wolf, 1993). RAN is thought to reflect efficient and fast matching of visual and phonological codes and is 
often found to be impaired in poor readers (Berninger et al., 2001; Bowers \& Ishaik, 2003; Bowers \& Wolf, 1993; Caravolas et al., 2012; Caravolas, Lervåg, Defior, Málková, \& Hulme, 2013; Vaessen, Gerretsen, \& Blomert, 2009). While some investigators suggested that RAN and PA might be different manifestations of the same underlying PA deficit (e.g., Clarke, Hulme, \& Snowling, 2005; Torgesen, Wagner, \& Rashotte, 1994; Vaessen et al., 2009), the double-deficit theory proposed that RAN constitutes a separate factor in dyslexia, independent of PA problems (Wolf, 1997; Wolf \& Bowers, 1999). Regardless of this ongoing discussion, there is a unique and strong (predictive) association between RAN and reading failure (de Jong \& van der Leij, 1999; McBride-Chang \& Manis, 1996; Puolakanaho et al., 2008; Vaessen et al., 2009). Also, twin studies indicated that RAN deficits in dyslexics are significantly heritable (Byrne et al., 2006; Davis et al., 2001; Gayan \& Olson, 2001; van Bergen, de Jong, Maassen, \& van der Leij, 2014) and RAN performance shows a similar parametric variation from healthy to at-risk non-dyslexic readers to at-risk dyslexic readers, as does PA (Pennington \& Lefly, 2001; Puolakanaho et al., 2008).

A third candidate vulnerability marker of reading disability is letter-speech sound processing (LS). This process can be defined into two sub-processes: letter-to-sound mapping and automatic letter-speech integration. Letter-to-sound mapping is relatively fast. Most children learn this within months of reading education (Seymour, Aro, \& Erskine, 2003). In contrast, automatic integration of letter-speech sound pairs takes much longer during development, even in normal readers (Froyen, Bonte, Van Atteveldt, \& Blomert, 2009; Froyen, Van Atteveldt, Bonte, \& Blomert, 2008). Poor readers are significantly slower in processing LS pairs than normal readers over six primary school grades, indicating persistent problems to efficiently and automatically integrate letters to speech sounds (summerized in Blau, Van Atteveldt, Ekkebus, Goebel, \& Blomert, 2009; Blau et al., 2010; Blomert \& Vaessen, 2009; Blomert, 2011; Froyen, Willems, \& Blomert, 2011). This LS learning deficit is already present in a core group of children at-risk for dyslexia before they start to read (Blomert \& Willems, 2010). Recent neuroimaging results showed that the reduced neural LS integration activity can be moderately improved by an intensive letter-speech sound coupling training next to regular reading instruction (Zaric et al., 2015). Similar to PA and RAN, at-risk non-dyslexic as well as at-risk dyslexic children were both found to demonstrate slow acquisition of letter-speech sound knowledge (Puolakanaho et al., 2008; Snowling et al., 2003).

A fourth potential reading-related risk factor might be verbal working memory (VWM). Although reduced performance on tasks of verbal working memory involving phonologically represented material are often reported in struggling readers (Beneventi, Tønnessen, Ersland, \& Hugdahl, 2010; Berninger et al., 2006; Georgiou, Das, \& Hayward, 2008), the exact role of a VWM deficit in dyslexia has been disputed. For example, it has been shown that memory span deficits in dyslexic readers are mainly restricted to tasks with a phonological component (Blomert \& Vaessen, 2009; Carroll \& Snowling, 2004; Felton \& Brown, 1990; Tijms, 2004) whereas their performance on tasks without this verbal component (e.g., spatial working memory) is comparable to that of non-dyslexic readers (Jeffries \& Everatt, 2004; Kibby, Marks, Morgan, \& Long, 2004). This has led to the debate whether VWM impairments are uniquely related to poor reading outcome, independent of phonological problems (Georgiou et al., 2008; McCallum et al., 2006) or not (Tijms, 2004). Nevertheless, a VWM deficit seems a candidate vulnerability marker since it predicts reading development (Georgiou et al., 2008; McCallum et al., 2006) and is subject to genetic effects already prior to schooling (e.g., Byrne et al., 2006). VWM deficits are shared by at-risk reading impaired and at-risk non-impaired children (Pennington \& Lefly, 2001).

Finally, we return to the validity of an IQ-reading performance discrepancy criterion traditionally used to identify reading disability assuming that the cause of reading failure might vary between low and high IQ readers. Current working definitions have not fully eliminated its use as an exclusionary criterion, defining dyslexia to be unexpected and a 'specific' learning deficit (e.g., Lyon et al., 2003). The use of discrepancy criterion in the diagnosis of dyslexia has been challenged from its inception though. Behavioral findings reveal that discrepant and non-discrepant poor readers did not differ in terms of long-term prognosis, severity of their PA deficits or response to intervention (for a review; Jiménez, Siegel, O’Shanahan, \& Ford, 2009; Stanovich \& Siegel, 1994; Stuebing et al., 2002; Stuebing, Barth, Molfese, Weiss, \& Fletcher, 2009). Practical and psychometric problems also caused identification of dyslexia solely based on an IQ-reading discrepancy or strict cut-off scores to become (Lyon, 1989, 1995). Moreover, recent neuroimaging studies confirm the lack of validity of the IQ-reading discrepancy definition of dyslexia by showing that regardless of IQ, dyslexic readers show similar functional organization of the brain network involved in phonological processing of print (Simos, Rezaie, Papanicolaou, \& Fletcher, 2013; Tanaka et al., 2011). Although the behavioral and neuroimaging profiles of poor readers do not seem to differ as a function of IQ recent genetic twin studies found that the degree of genetic influences does vary as a linear function of IQ. More specific, reading failure in high-IQ dyslexics are due to substantially genetic causes whereas the etiology of reading failure in low-IQ dyslexics seem to be due to more environmental causes (Knopik et al., 2002; Wadsworth et al., 2000; Wadsworth, Olson, \& DeFries, 2010). The existence of two potential etiologies for childhood reading disability was confirmed by a neuroimaging study by Shaywitz and Shaywitz (2005) indicating a predominantly genetic, specifically impaired reading impaired type with IQ scores over 100 and a more environmentally influenced type with IO scores below 100. Thus, although the same genetic factors could be operating across varying levels of IQ genetic influence is stronger in high-IQ dyslexics which may require different or more thorough remediation.

Previous poor reader classification attempts focused on the above described cognitive vulnerability markers are rather limited and can be divided into two major categories. The first category employs a top-down, theory-driven approach, classifying subjects into one of the hypothesized subtypes by means of a predefined division (Compton, DeFries, \& Olson, 2001; Wolf \& Bowers, 1999; Zoubrinetzky, Bielle, \& Valdois, 2014). The second type of classification studies employs bottomup, data-driven, analysis in large representative samples of children which provides the opportunity to explore distinct profiles without making a priori assumptions on the nature and number of the expected subtypes. An advantage of such 
data-driven classification over theory-driven studies is that they circumvent possible limitations of the boundaries of the theoretical model and look beyond this adopted framework to find different, emerging subtypes (Heim et al., 2008; King, Giess, \& Lombardino, 2007; Morris et al., 1998; Pacheco et al., 2014). Several data-driven studies focused on reading abilities in unselected samples of children, but not on the underlying cognitive deficits (e.g., Buly \& Valencia, 2002; Pierce, Katzir, Wolf, \& Noam, 2007). Others have investigated reading problems as one manifestation of learning disabilities amongst a widespread range of deficits in general language, reading, perceptual, motoric and other cognitive processes (e.g., Morris et al., 1998; Rourke, 1985; Satz \& Morris, 1981). The data-driven classification study by King et al. (2007) did focus on reading impaired children, using PA and RAN as main clustering variables. Results revealed evidence for three impaired subtypes of distinct underlying cognitive deficits, namely one phonological deficit profile, a rapid naming deficit profile and a profile reflecting a double deficit in both domains. Another more recent clustering study by Pacheco et al. (2014) focused on a wider range of cognitive abilities when profiling dyslexic children with normal-range IQ scores, including measures of PA, RAN, VWM and vocabulary. Results suggested a cluster with phoneme deletion and RAN deficiencies and a cluster with phonological processing difficulties (phoneme deletion and digit span) without a RAN deficit. A limitation was the small sample size of 37 children. The present clustering attempt will further explore this broader cognitive spectrum of poor reading across these reading-related vulnerability markers in a much larger and representative sample of grade 2 to 4 poor readers. We will moreover also take into account recent major advances in the genetic underpinnings of reading disability by adding information on the familial occurrence of reading problems in addition to possible environmental influences. Since genetic influence varies with the level of IQ, we moreover included non-verbal IQ as a general cognitive clustering variable not as an inclusion criteria like in the study of Pacheco and colleagues (2014).

\subsection{The present study}

The present, data-driven clustering study was executed within a large sample of second to fourth grade poor readers between 7 and 10 years old. We aimed to explore the possibility of identifying distinct types of reading disability and investigated whether these cognitive profiles can differentiate between poor readers with a family history of dyslexia and those influenced mainly by environmental factors. We hypothesize that a strong familial risk should be reflected in disabled reading skills and also in underlying cognitive deficits. Cognitive clustering was based on a 200 multi-start $K$-means approach with the following vulnerability markers of reading failure: phonological awareness (PA), rapid naming (RAN), letter-speech sound processing accuracy and response time (LS) and verbal working memory (VWM) as clustering variables, next to general cognitive abilities of non-verbal IQ and vocabulary. Subsequently, the obtained subtypes were compared on characteristics of familial risk (i.e., first-degree family member with severe childhood reading and spelling difficulties), environmental risk factors (i.e., socio-economic status and reading performance level at schools) and co-morbidity characteristics (i.e., arithmetic deficits and ADHD characteristics).

\section{Methods}

\subsection{Participants}

The current sample of poor readers investigated in the present study consisted of 334 children (i.e., 155 girls; $n=134$ in grade $2 ; n=111$ in grade $3, n=89$ in grade 4 ) obtained from two larger samples:

- The first sample is an unselected school sample of 1717 children (i.e., all children in one classroom were evaluated) enrolled in 13 primary schools spread across 5 different regions in the Netherlands. This sample was originally used for the standardization of the 3DM test battery (i.e., psycho-metric Differential Diagnosis Dyslexia Maastricht (3DM), Blomert \& Vaessen, 2009);

- The second sample consisted of 108 children attending regular primary school that were also referred to a specialized dyslexia institute in their region to further investigate their reading or reading-related development. These children were also part of the norming and validation study by Blomert and Vaessen (2009) and tested at the dyslexia institute.

Children were labeled as poor readers if they performed one standard deviation below the mean norm score (i.e., percentile score $<16$ ) on a Dutch standardized word reading fluency test of the 3DM test battery (Blomert \& Vaessen, 2009). Based on this selection criterion the following poor reading samples emerged:

- In the first sample, 257 children of 1717 met the present's study poor reader criterion;

- In the second sample, 77 of 108 children were labeled as poor readers.

All children were native Dutch speakers. Note that the Dutch school system approves the use of a handful of reading instruction protocols of which the basic principles of instructions focus on developing awareness of the basic phonological structure of written language in addition to learning the important letter-speech sound relations in isolation and in the context of structured words. As a consequence, the reading instruction and interventions provided at Dutch schools are highly comparable. This is further guaranteed by the national protocol for reading intervention, or the pupil evaluation 
Table 1

Age and mean performance of overall poor reader group on cognitive tasks.

\begin{tabular}{|c|c|c|c|c|}
\hline & \multicolumn{2}{|c|}{ Raw scores } & \multicolumn{2}{|c|}{ Standardized scores ${ }^{\mathrm{a}}$} \\
\hline & $M$ & $S D$ & $M$ & $S D$ \\
\hline \multicolumn{5}{|l|}{ Age and general cognitive performance } \\
\hline Age (years) & 8.90 & 0.99 & n.a. & n.a. \\
\hline Non-verbal IQ (mean 100, SD 15) & n.a. & n.a. & 99.15 & 13.95 \\
\hline Vocabulary (\% correct) & 72.93 & 8.80 & 0.10 & 0.97 \\
\hline Baseline rt (s/item) & 0.97 & 0.22 & -0.15 & 0.89 \\
\hline \multicolumn{5}{|l|}{ Reading and spelling performance } \\
\hline Reading fluency 3DM (correct/s) & 0.66 & 0.26 & -1.62 & 0.55 \\
\hline Reading fluency OMT (correct/s) & 0.49 & 0.22 & -1.49 & 0.76 \\
\hline Reading fluency Klepel (correct/s) & 0.18 & 0.08 & -1.38 & 0.51 \\
\hline Spelling acc 3DM (\% correct) & 61.01 & 16.10 & -0.98 & 0.91 \\
\hline Spelling-to-dictation (\% correct) & 34.03 & 17.29 & -0.71 & 1.01 \\
\hline \multicolumn{5}{|l|}{ Reading-related risk markers } \\
\hline PA (\% correct) & 44.21 & 24.34 & -0.90 & 0.87 \\
\hline RAN letters (s/15 items) & 10.97 & 2.67 & -0.64 & 0.92 \\
\hline RAN digits (s/15 items) & 11.81 & 2.99 & -0.93 & 0.96 \\
\hline LSSI acc $(\% \text { correct })^{\mathrm{b}}$ & 90.73 & 7.64 & -0.52 & 1.10 \\
\hline LSSI rt (s/item) & 2.55 & 0.63 & -0.63 & 1.04 \\
\hline LSSD acc $(\% \text { correct })^{b}$ & 82.91 & 10.46 & -0.59 & 1.02 \\
\hline LSSD rt (s/item) & 1.84 & 0.55 & -0.31 & 1.09 \\
\hline VWM (acc) & 10.38 & 2.22 & -0.31 & 0.96 \\
\hline
\end{tabular}

Note. Reading fluency is items correct/second.

PA, phonological awareness - phoneme deletion; RAN, rapid naming; LSSI, letter-speech sound identification; LSSD, letter-speech sound discrimination; VWM, verbal working memory; acc, accuracy; rt, response time; n.a., not available.

a Standardized scores: IQ expressed in IQ scores (mean $=100, S D=15$ ). Performance on reading, spelling and reading-related vulnerability markers expressed in $z$-scores.

b Chance level on LSSI 25\% correct, LSSD 50\% correct.

system, dictating schools how to monitor and remediate children struggling with their literacy development. An informed consent from all parents/caregivers and permission from the Ethical Faculty Committee was obtained. Age and mean performance (raw and standardized $z$-scores) of the poor reader sample on literacy tasks and on the general cognitive and the reading-related tasks subsequently used for clustering are presented in Table 1. We used SPSS (version 21). The overall poor reader sample was on average $8.9( \pm 0.99)$ years old and showed general cognitive abilities that fell within the average range. They moreover showed a disabled performance on all reading and spelling tasks (confirming the employed poor reader selection criterion). Finally, the poor readers demonstrated poor to low-average PA, LS, RAN and VWM skills.

\subsection{Procedure}

Children were tested at their school or dyslexia institute in a quiet room. Tasks were administered individually, in a fixed order by trained project workers (except for the classically administered non-verbal IQ). Independent Dutch national norms for the 3DM test battery range from grade 1 to the end of grade 6 of primary school and all subtest were computerized, using a specially designed response-box to precisely measure accuracy and/or response time in milliseconds. Independent Dutch national norms were also available for all other included tasks (norm range included in the task description below) and were all paper-to-pencil tasks. Please note that the performance from all children from the original norming and validation study of the 3DM study by Blomert and Vaessen (2009) were used for the present study. Thus, the 3DM tests (or other included measures) were not administered previously, excluding a possible influence of multiple testing with the same test battery.

\subsection{Tasks}

\subsubsection{Poor reader criterion - Reading fluency (3DM)}

Children read aloud as many singly presented words as quickly as possible on 3 levels (high-frequent, low-frequent, pseudo-words, 75 items in 30 s per level on 5 screens, 15 items). Fluency was an overall composite score over 3 levels expressed in number of correct words (items/second) and used to define the poor reader criterion (i.e., the lowest 16th percentile). Test-retest reliability coefficient was 0.95 (reported in the test manual of 3DM).

\subsubsection{Initial clustering variables}

2.3.2.a. Phonemic awareness - Phoneme deletion (PA 3DM). The task presented 23 pseudo-words via headphones. The child deleted a speech sound at different positions and pronounced the resulting pseudo-word (e.g., “/dauk/ - /d/, what is left?”). 
Accuracy (\% correct) and response time (seconds/item) was measured but RT was excluded from further analyses due to floor accuracy performance in $1 / 3$ of children (i.e., $\leq 5$ items correct). The task had an internal consistency of 0.85 for accuracy and 0.93 for speed (reported in the test manual of 3DM).

2.3.2.b. Rapid naming ( $R A N 3 D M)$. The child named items on a sheet (letter and digit task) as quickly as possible (i.e., 2 sheets per task, 15 items per sheet in different order). Response time was mean RT over two sheets. The naming task had a split-half reliability of 0.80 (reported in the test manual of 3DM).

2.3.2.c. Letter-speech sound processing ( $L S$ SDM). Two tasks were used to measure accuracy and response time of letterspeech sound knowledge, a letter-speech sound identification task and a letter-speech sound discrimination task. In the letter-speech sound identification (LSSI) task, a phoneme was presented over headphones (in total 45 unique trials) simultaneously with four letters ( or letter combinations) appearing on a screen (e.g. / b/ and ' $b$ ' ' $d$ ' ' $t$ ' ' $p$ '). The child identified the corresponding letter-speech sound pair by pressing the button matching to the correct letter. In the letter-speech sound discrimination ( $L S S D$ ) task, a speech sound was presented via headphones (90 in total) simultaneously with one visual letter (or letter combination). By pressing a button, the child indicated whether the letter and the sound were the same or different (e.g. /o/ and 'a'). Accuracy (\% correct) as well as response time (s/item) was measured for both tasks. The accuracy scores of the LSSI and LSSD tasks had an internal consistency of respectively 0.72 and 0.82 and the speed scores of the LSSI and LSSD tasks had an internal consistency of respectively 0.90 and 0.96 (reported in the test manual of 3DM).

2.3.2.d. Verbal working memory (VWM). Digit span (WISC-R) required children to repeat a digit sequence in forward or backward order (de Bruyn, van der Steenen, \& van Haasen, 1986). The sequence length increased from 2 to 9 digits and 2 trials per sequence length were offered. The task was stopped if both trials of a given length were incorrect. Accuracy score was the sum of the largest correctly repeated forward and backward sequence. The digit span test had a split-half reliability of 0.78 (reported in the test manual WISC-R). The Dutch version of WISC-R has norms for children between 6 and 16 years of age.

2.3.2.e. Non-verbal IQ. RAVEN-CPM required children to identify missing segments required to complete a larger pattern to measure non-verbal IQ at schools (Van Bon, 1986) For the Dutch version of this task, reliabilities of 0.80 and higher were reported. WISC-R-NL Block design measured IQ at the dyslexia institutes (WISC-R: de Bruyn et al., 1986). Children copied geometric designs with four or nine plastic cubes. The reliability coefficient for the Block Design subtest in a Dutch population is between 0.88 and 0.89 . To compare RAVEN and WISC performance, both scores were transformed into an IQ estimate (median $=100, S D=15$ ). The transformed IQ scores did not differ significantly for RAVEN and WISC, respective values were 98.26 (14.64) and $101.42(14.35), t(1)=2.77, p>0.05$. Normative data for RAVEN-CPM ranged from 5 to 11 years of age (for norm range of WISC-R see VWM section above).

2.3.2.f. Receptive vocabulary. Children matched one of four pictures to an orally presented word (RAKIT; Bleichrodt, Drenth, Zaal, \& Resing, 1988). Accuracy was expressed in \% correct (maximum items 60). The test has an internal consistency of 0.81 (reported in the test manual Rakit). Dutch norms were available for children from 4 to 11 years of age.

2.3.2.g. Baseline response time (3DM). An animated figure (20 in total) appeared in one of four squares on the screen. The child identified the location of the figure by pressing the corresponding button as fast as possible. The task has an internal consistency of 0.93 (reported in the test manual of 3DM).

\subsubsection{Comparing clusters: Reading and spelling}

2.3.3.a. Reading fluency. Children read aloud single words as quickly as possible in the presented time: One-Minute test (OMT: high and low frequent words, 1 min, Brus \& Voeten, 1973), Klepel (pseudo-words, 2 min, van den Bos, Lutje Spelberg, Scheepstra, \& de Vries, 1994) and 3DM reading fluency used for the initial poor reader selection (for a description see above). Fluency was expressed in correctly read words (items/second). Test-retest reliabilities are reported to be over 0.80 for the OMT, 0.89 for the Klepel and 0.95 for 3DM reading fluency. Dutch norms ranged from grade 1 to the first class of secondary school for both the OMT and the Klepel (for norm range of 3DM see Procedure section above).

2.3.3.b. Spelling. Two spelling tasks were administered. Spelling-to-dictation (PI-dictee, Geelhoed \& Reitsma, 1999): 135 words were dictated to the child in a sentence (i.e., from simple words to multi-syllable words with complex spelling rules) until 8 or more incorrect spellings in one block of 15 sentences were made. The internal consistency of this standardized test is between 0.90 and 0.96 (reported in the PI-dictee test manual). Dutch norms are available for children from grade 1 to 6. Computerized spelling task (3DM): an auditory word (e.g., /boom/) was presented via headphone simultaneously with a visual, incomplete word (e.g., / were presented (e.g., 'oo', 'a', 'o', 'aa'). The child selected the option to complete the word correctly by pressing a corresponding button. Accuracy was expressed in \% correct. The task accuracy measure has an internal consistency of 0.80 (reported in the manual of 3DM). 


\subsubsection{Comparing clusters: Reports on familial risk, co-morbidity and environmental factors}

The emerging subtypes were compared on familial risk for dyslexia, environmental risk factors (school performance level, socio-economic status (SES) based on parental education and on neighborhood status) and co-morbidity characteristics were obtained through parent-ratings on a reading-status questionnaire ( $F A D D$, Blomert, unpublished).

2.3.4.a. Familial risk for dyslexia. A child was defined as at-risk for dyslexia if at least one first-degree family member (i.e., a parent or sibling) indicated to have suffered from severe childhood reading and spelling difficulties.

2.3.4.b. Environmental factors. Parental Education Level SES. Parental education was assessed on a 5-point scale ranging from 'primary school' to 'vocational bachelor or university level' (i.e., 5 levels ranging from low, low average, average, high average or high parental education). For the current analyses we defined two socio-economic status categories: poor parental education for low to low average and normal parental education for the remaining level. Neighborhood SES. This neighborhood social status score was adopted from extensive research by the Netherlands Institute for Social Research (Knol, 2012). A factor analyses defined the status score of each Dutch postal code area based on four characteristics of neighborhood residents within each area: mean income, percentage low incomes, percentage of low educated residents and percentage of unemployed residents (i.e., scores ranged from -7.25 to 3.19, a low score indicates low neighborhood status, average score in 2010 was of 0.17 ). For the current analysis, we defined two neighborhood social status categories: poor neighborhood status with a status score of 1 standard deviation below the mean norm and a normal neighborhood status.

2.3.4.c. School reading performance level. Within the original, unselected grade 1-6 school sample $(n=1717)$ from which the present grade 2-4 poor reader sample $(n=334)$ was selected, we evaluated the overall proportion of poor reading children based on the 3DM reading fluency performance of $1 S D$ below the norm (i.e., the 16th percentile). Overall proportions of poor readers were set for all 13 participating schools. Next, we ranked the 13 schools based on a median cut-off (i.e., $\leq 13.33 \%$ ) we divided the schools in two categories: lower reading level schools and higher reading level schools. More specific, 7 schools were labeled as low proportion of poor reader schools and 6 schools as high proportion of poor reader schools.

2.3.4.d. Co-morbidity characteristics. Parent-ratings on the FADD questionnaire indicated presence/absence of severe arithmetic difficulties for a minimum period of 6 months. Parent-ratings on the AVL questionnaire (Scholte \& van der Ploeg, 2005) consisting of 18 questions on attention, concentration and (hyper)activity indicated whether the child exhibited behavioral symptoms of ADHD for the last 6 months or more. The overall score resulted in three categories; ADHD symptoms were low, moderate or considerably present, of which the latter category was considered ADHD behavior.

\section{Results}

\subsection{Data preparation}

The present data-driven, clustering approach investigated the possibility to identify distinct types of underlying cognitive deficit patterns in a large sample of poor readers and subsequently explored the relation between these subtypes and familial risk and environmental factors contributing to reading failure. This statistical classification approach was previously employed to successfully identify distinct cognitive subtypes within an independent heterogeneous sample of children with arithmetic difficulties (Bartelet, Ansari, Vaessen, \& Blomert, 2014). We now apply it in the context of reading disability. Note that all variables scores were nationally normed measures (i.e., normally distributed and corrected for age ensuring that a child's performance is compared to children that received a similar amount of reading instruction). For all analyses, the scores on each measure were transformed into standardized $z$-scores to ensure that differences in measurement scale did not influence the results.

In order to distinguish theoretically meaningful latent variables we first conducted an exploratory factor analysis (principal components with oblimin rotation) on the eight reading-related vulnerability markers: phonological awareness accuracy (PA), rapid naming speed (RAN) letters and digits, letter-speech sound (LS) identification and discrimination accuracy and response time, and verbal working memory accuracy (VWM). LS response time tasks were corrected for possible individual motor response differences (i.e., tendency to work fast/slow resulting in a possible speed/accuracy tradeoff) prior to the factor analysis. Specifically, we regressed baseline response time (with a similar design to the LS tasks) on the LS RT to subsequently compute corrected RT residuals. This baseline RT tasks was thus not separately included in the factor or subsequent analyses. Note that post hoc comparisons revealed that baseline response time was comparable across emerging clusters (type $1: M=-0.07, S D=1.08$, type $2: M=-0.16, S D=1.03$, type $3: M=-0.15, S D=1.04$ and type 4 : $M=-0.21, S D=1.19, F(3,330)=0.22, p=0.88)$. The factor solution for the current reading disabled sample resulted in the following five theoretically relevant factors with eigenvalues of at least 0.70 (Jolliffe, 1986) and a communality estimate of at least 0.70 (MacCallum, Widaman, Zhang, \& Hong, 1999): phonological awareness (PA; accuracy), rapid naming (RAN; reaction time on letters and digits), letter-speech sound accuracy (LS accuracy; on identification and discrimination), letterspeech sound fluency (LS rt; reaction time on identification and discrimination) and verbal working memory (VWM; 
Table 2

Results of exploratory factor analysis.

\begin{tabular}{|c|c|c|c|c|c|c|}
\hline & \multicolumn{4}{|l|}{ Factors } & \multirow[b]{2}{*}{ VWM } & \multirow[b]{2}{*}{ Communalities } \\
\hline & PA & RAN & LSacc & LSrt & & \\
\hline PA acc & 0.89 & 0.01 & 0.10 & -0.05 & -0.20 & 0.91 \\
\hline RAN digits & -0.19 & 0.81 & 0.08 & -0.01 & 0.27 & 0.79 \\
\hline RAN letters & 0.18 & 0.86 & -0.7 & 0.04 & 0.22 & 0.81 \\
\hline LSSI acc & 0.11 & 0.02 & 0.90 & 0.17 & 0.13 & 0.82 \\
\hline LSSD acc & -0.04 & -0.03 & 0.80 & -0.22 & -0.12 & 0.76 \\
\hline LSSI rt & -0.10 & 0.03 & 0.09 & 0.76 & -0.15 & 0.76 \\
\hline LSSD rt & 0.03 & 0.00 & -0.06 & 0.90 & 0.03 & 0.81 \\
\hline VWM acc & 0.18 & 0.01 & -0.02 & 0.08 & -0.91 & 0.90 \\
\hline Eigen values & 2.39 & 1.88 & 1.13 & 0.93 & 0.80 & \\
\hline
\end{tabular}

Note. Principal component analysis with oblimin rotation.

PA, phonological awareness - phoneme deletion; RAN, rapid naming; LSSI, letter-speech sound identification; LSSD, letter-speech sound discrimination; VWM, verbal working memory; acc, accuracy; rt, response time.

accuracy). Factor loadings and eigen values of the five extracted factors, which had a cumulative explained variance of $77 \%$, are presented in Table 2.

\subsection{Identifying clusters of reading disability}

Nonverbal IQ vocabulary performance and the five identified factors were entered as variables in the subsequent clustering analyses conducted with SPSS (version 21). We firstly conducted an Agglomerative hierarchical clustering approach (Ward's method) as a pre-processing step in our data analyses. Specifically, this bottom-up clustering approach provides us with the mechanism for monitoring data merging, on the one hand and, on the other, a strategy to determine the optimal number of clusters representing the data. The analysis initially starts with every single case within a separate cluster, considering each individual case separate from all the others. Subsequently, cases are merged (i.e., agglomerated) together into new clusters based on highest similarity in each following iteration. Similarity is based on the lowest increase in error of sum-of-squares or in other words the smallest distance to the cluster center (i.e., SUMD). This merging process is continued until all of the data is merged into one cluster (Field, 2005; Sarstedt \& Mooi, 2014). Thus, clusters generated in early stages are nested in those generated in later stage which is reflected in the hierarchy of the clustering tree plot. The results can be described in a dendrogram (Fig. 1 - bottom) and a plot of the mean sum-of-squares (mean SUMD) as a function of $K$ number of clusters (Fig. 1 - top). The dendrogram visualizes the hierarchy within the final cluster in which each iteration merge is represented by a binary tree. Interpreting the height between the different nodes and its leaf indicated that the largest threshold distances can be seen at four clusters. The optimal four cluster solution best representing the data was further confirmed by the observed 'elbow' at $K=4$ (i.e., while the average sum-ofsquares monotonically decreased for increasing $K$ ( 1 to 4 ), this decrease reduces markedly for $K>4$ ) in the mean SUMD plot. Hierarchical agglomerative clustering thus provided us with the optimal indication of the number of clusters represented in our data. However, using this approach for clustering alone, although leading to a cluster grouping of our data, only leads to one possible (and possibly sub-optimal) solution. Hence, we applied a second step, employing $K$-means clustering.

Iterative partitioning $\mathrm{K}$-means multi-start (200 runs) clustering approach (Euclidean distance) provided us with a mechanism for assessing different configurations (cluster solutions) based on multiple initializations to subsequently identify the cognitive profiles of these four clusters estimated to be the best fit of the current data. $K$-means clustering performs an iterative fitting process to form the specified optimal number of clusters $(K=4)$. This is done by selecting a set of cluster seeds as a first guess of the starting point as the initial cluster centers. Subsequently, each case is assigned to one of the four clusters it most closely resembles, after which the cluster mean is re-calculated. This process continues until the clusters stabilize. The choice of this initial starting point for clustering can greatly affect the resulting classification which may be a sub-optimal representation of the data (King et al., 2007). However, by re-sampling the data 200 times using MATLAB (2001), using randomly chosen, cluster centers to start clustering from, we circumvent the well-known problem of local optima. We moreover can guarantee that the final four cluster solution obtained (i.e., the most optimal fit out of 200 runs) represented the clustering result with the minimal sum of average squared distances within clusters. In other words, we would ensures maximal cluster stability and obtain the result that reduces the Euclidean distance most effectively, represents the global optima or best fit of the data (Steinley, 2006). The best fitting four-cluster solutions resulting from this multi-start $K$-means revealed the following cognitive profiles of reading disability (standardized $z$-scores of the mean performance on the classification variables per cluster are presented in Table 3 , for a visual representation of this data see Fig. 2):

Type $1(n=86)$ holds poor readers with average general cognitive IQ, vocabulary and average performance on PA, RAN, LS and VWM ( $z$-scores ranging between 0.46 and -0.50). This type thus showed difficulties with reading without showing underlying general of reading-related cognitive deficits and was therefore labeled reading-only impaired readers. 

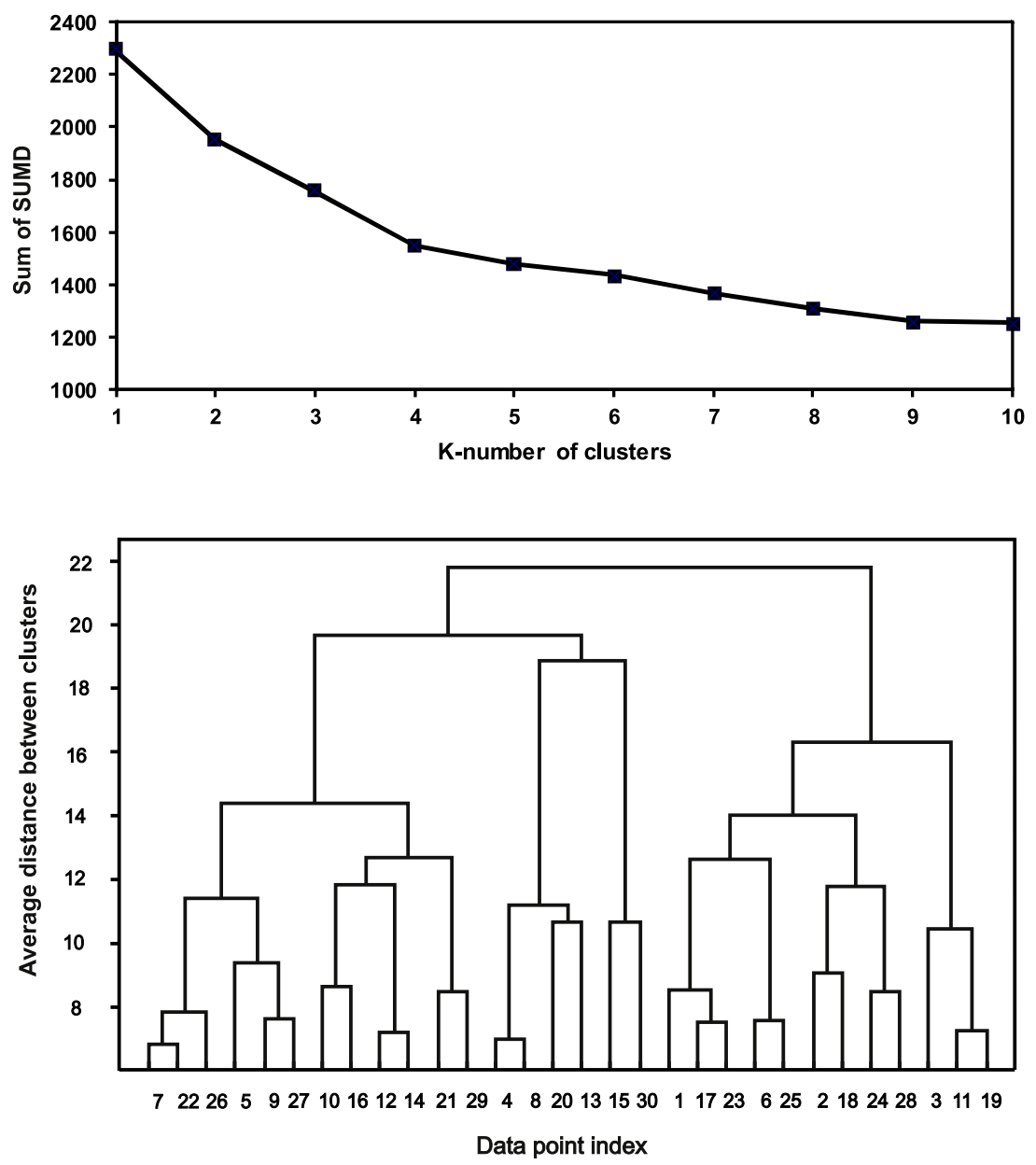

Fig. 1. Identifying optimal number of clusters. (Top) -Total sum-of-squared within cluster distances (SUMD) as a function of $k$-number of clusters. Note that the total SUMD shows an 'elbow' at $K=4$ and that after that the decrease of total SUMD is markedly reduced, indicating four as the optimal number of clusters representing the data. (Bottom) - Dendrogram plot of the agglomerative hierarchical binary cluster tree (Wards linkage, Euclidean distance). The Dendrogram is collapsed over lower branches to increase visibility of the plot (some nodes in the plot thus correspond to more than one data point). The largest threshold distances (i.e., height between the node and the leaf) can be seen at four clusters.

Type $2(n=76)$ showed low IQ and vocabulary ( $z$-scores of -0.84 and -0.81 , respectively) which were in correspondence to their low-to-poor performance across all reading-related skills, indicated by impaired PA ( $z$-score of -1.35$)$, low-average RAN ( $z$-score between -0.75 and -0.84 ), low-average-to-poor LS accuracy and RT ( $z$-score between -0.52 and -1.07 ) and poor VWM ( $z$-score of -0.99$)$. Thus, this type consisted of general poor readers.

Type $3(n=79)$ poor readers exhibited low-average IQ scores $(z$-score of -0.46$)$ and normal vocabulary $(z$-score of 0.06) next to a specific impairment in LS processing (Accuracy $z$-score between -1.09 and -1.54 ) and PA ( $z$-score of -1.16). Their performance on RAN and VWM performance where in the average norm range ( $z$-score between -0.55 and -0.10$)$. Note that these children performed average on LS processing speed. This type was labeled PA-LS specific poor readers.

Type 4 ( $n=93$ ) poor readers showed average IQ and vocabulary (i.e., a $z$-score of 0.55 on both measures) discrepant to their impaired RAN and PA performance (respective $z$-scores were -1.38 to -1.47 and -0.94 ). The performance on LS accuracy, LS RT and VWM was in the low average range (z-scores ranging between -0.49 and -0.72 ). This type was labeled as PA-RAN specific poor readers. Note. A cross-validation confirmatory analysis (i.e., randomly split the present poor reader sample in half to repeat the clustering approach for each sub-sample using the 200 multi-start procedure) yielded the same four cognitive types of poor reading as described above. To further confirm that a four-cluster solution was the best fit for the present data, we also explored a five and six-cluster solution. Both analyses revealed the same important clusters as four-cluster solution, and although additional cluster(s) emerged, none corroborated any poor reader types predicted by theoretically relevant models of poor reading (e.g., no additional speed/RAN-only disabled type of poor reading, predicted by the double-deficit hypothesis), confirming the validity of the emerging optimal four cluster solution. 
Table 3

Mean performance and standard deviations on general cognitive variables and reading-related vulnerability markers per poor reader type.

\begin{tabular}{|c|c|c|c|c|c|c|c|c|c|c|}
\hline & \multirow{3}{*}{\multicolumn{2}{|c|}{$\begin{array}{l}\text { Type } 1 \\
\text { Read-only } \\
n=86\end{array}$}} & \multirow{3}{*}{\multicolumn{2}{|c|}{$\begin{array}{l}\text { Type } 2 \\
\text { Gen poor } \\
n=76\end{array}$}} & \multirow{3}{*}{\multicolumn{2}{|c|}{$\begin{array}{l}\text { Type } 3 \\
\text { PA-LS } \\
n=79 \\
\end{array}$}} & \multirow{3}{*}{\multicolumn{2}{|c|}{$\begin{array}{l}\text { Type } 4 \\
\text { PA-RAN } \\
n=93\end{array}$}} & \multirow[t]{4}{*}{$F$-value } & \multirow[t]{4}{*}{ Post hoc } \\
\hline & & & & & & & & & & \\
\hline & & & & & & & & & & \\
\hline & $M$ & $S D$ & $M$ & $S D$ & $M$ & $S D$ & $M$ & $S D$ & & \\
\hline \multicolumn{11}{|l|}{ General cogn } \\
\hline IQ & 0.01 & 0.90 & -0.84 & 0.72 & -0.46 & 0.88 & 0.55 & 0.72 & $46.07^{*}$ & $4>1>2=3$ \\
\hline Vocabulary & 0.46 & 0.84 & -0.81 & 0.80 & 0.06 & 0.77 & 0.55 & 0.80 & $46.49^{*}$ & $4=1>3>2$ \\
\hline \multicolumn{11}{|l|}{ Read-related } \\
\hline PA & -0.23 & 0.72 & -1.35 & 0.65 & -1.16 & 0.87 & -0.94 & 0.80 & $33.55^{*}$ & $1>4=3>2$ \\
\hline RAN digits & -0.30 & 0.73 & -0.84 & 0.93 & -0.55 & 0.75 & -1.47 & 0.70 & $37.93^{*}$ & $1=3>2>4$ \\
\hline RAN letters & -0.12 & 0.70 & -0.75 & 0.90 & -0.10 & 0.72 & -1.38 & 0.73 & $56.66^{*}$ & $1=3>2>4$ \\
\hline LSSI acc & 0.14 & 0.86 & -0.52 & 1.02 & -1.09 & 1.06 & -0.64 & 1.07 & $21.52^{*}$ & $1>4=2>3$ \\
\hline LSSD acc & 0.16 & 0.74 & -0.56 & 0.92 & -1.54 & 0.73 & -0.49 & 0.91 & $58.06^{*}$ & $1>4=2>3$ \\
\hline LSSI rt & -0.50 & 0.86 & -1.07 & 0.88 & 0.01 & 0.97 & -0.72 & 1.01 & $18.51^{*}$ & $3>1>4=2$ \\
\hline LSSD rt & -0.39 & 0.87 & -0.84 & 0.82 & 0.75 & 0.89 & -0.55 & 0.88 & $51.06^{*}$ & $3>1>4=2$ \\
\hline VWM & 0.37 & 0.89 & -0.99 & 0.83 & -0.51 & 0.80 & -0.20 & 0.78 & $38.86^{*}$ & $1>4=3>2$ \\
\hline
\end{tabular}

Read-only, reading-only impaired readers; Gen Poor, general-poor readers; PA, phonological awareness - phoneme deletion; RAN, rapid naming; LSSI, letter-speech sound identification; LSSD, letter-speech sound discrimination; VWM, verbal working memory; acc, accuracy; rt, response time; performance of all tasks expressed in standardized $z$-scores.

${ }^{*} p<0.01$. For a visual representation of the data see Fig. 2.

\subsection{Comparison of types of poor readers on clustering variables}

Validation and interpretation are the two last steps of a clustering process. We firstly compared the obtained four types of poor reading on the initial cluster variables to be able to investigate on which specific clustering variables significant differences occurred between the poor reading subtypes. The subtypes of poor reading were compared on the clustering variables by means of analyses of variance (ANOVA). Type 1 (reading-only impaired reader) performed within the average range on all general cognitive and markers. Due to the already extensive nature of the results section, we list the most interesting significant differences between the other three subtypes of poor readers (Table 3 summarizes the comparisons and post hoc analyses, Bonferroni-corrected).

The three poor reader types in which we identified variable underlying patterns of cognitive deficits all showed a PA deficit, with type 2 (general poor readers) showing the most impaired PA skills. Significantly poorer LS accuracy was characteristic of type 3 (PA-LS specific poor readers), while type 4 (RAN-PA specific poor readers) and type 2 (general poor readers) did not differ. A significant RAN deficit was specific for type 4 (PA-RAN poor readers) revealing an inferior performance as compared to type 3 (PA-LS specific poor readers) and type 2 (general poor readers). Less impaired LS RT was found for type 3 (PA-LS specific poor readers) compared to type 2 (general poor readers) and type 4 (PA-RAN specific poor readers). Low VWM was characteristic of type 2 (general poor readers), while type 3 (PA-LS specific poor readers) and type 4 (PA-RAN specific poor readers) showed no difference. As for the general cognitive performance, type 3 (PA-LS specific poor readers) and type 4 (PA-RAN specific poor readers) IQ performance was within average range with the later showing superior IQ skills. The general poor readers showed below average IQ. Finally, Vocabulary was significantly better in type 4 (PA-RAN specific poor readers) than the general poor readers but not as compared to type 3 (PA-LS specific poor readers).

\subsection{External validity of the obtained poor reading types}

Next, the obtained poor reading subtypes were compared on external validation variables, independent of the initial classification variables. First, age and reading and spelling fluency of the four subtypes were compared by means of an ANOVA (Table 4 lists mean $z$-scores and standard deviations per subtype and the comparisons and post hoc analyses, Bonferroni-corrected). The reading-only impaired type was significantly younger (i.e., 5 months) than the other three types of poor reading that did not differ. However, there was no significant difference between the proportion of children attending grade 4, grade 5 or grade 6 between the subtypes. This subtype also showed significantly less impaired reading fluency skills on all three reading fluency measures than the other three types that did not differ in their severity of reading deficit. This poor reader type actually performed low average both spelling tasks, while the other three types that did not differ significantly, performed below average.

Second, familial risk for dyslexia and environmental risk factors (i.e., SES based on parental education, SES based on social neighborhood status and poor school performance level) expressed in proportions were compared (Table 5 lists the proportions per subtype in addition to the chi-square comparison). The PA-RAN specific deficit poor readers (type 4) showed a significantly larger familial risk (63\%) as compared to the other three types that did not differ from each other (19\% in type 1, 24\% in type 2 and 20\% in type 3). Please note that information for 7 children in the PA-RAN type was missing. Familial risk 


\section{Type 1 - Reading-only impaired poor readers}

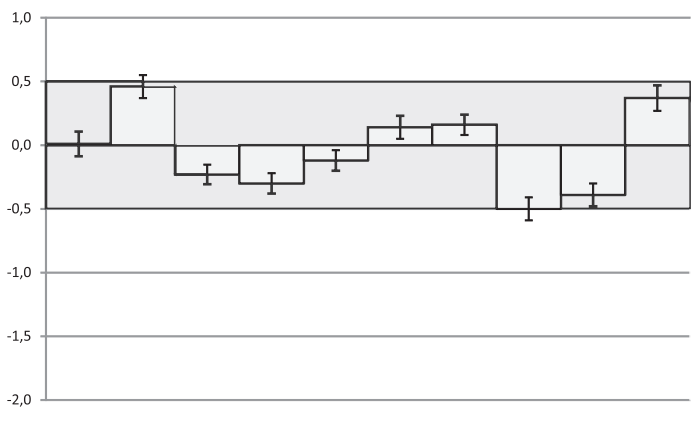

Type 2 - General poor readers

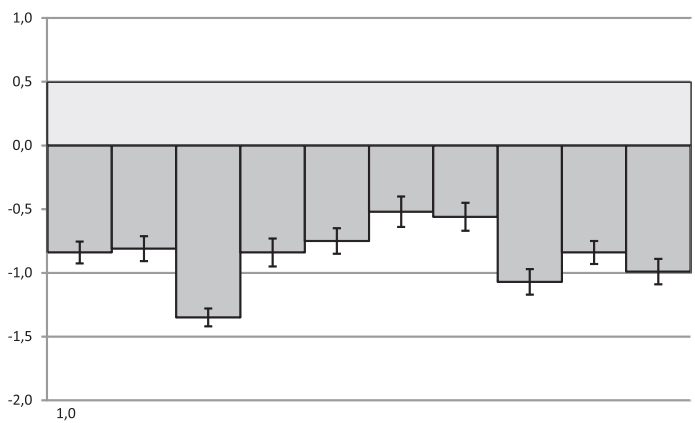

Type 3 - PA-LS specific poor readers

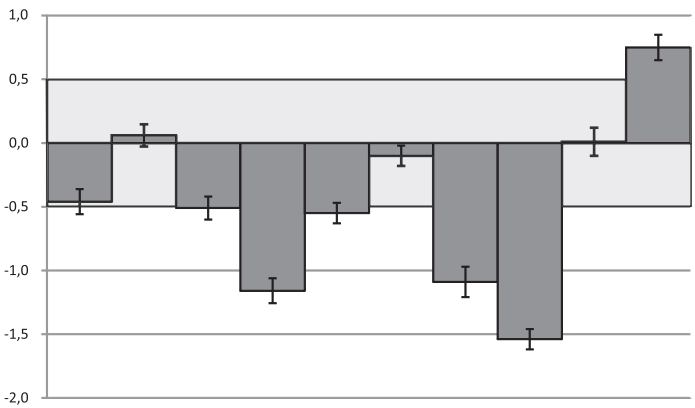

Type 4 - PA-RAN specific poor readers

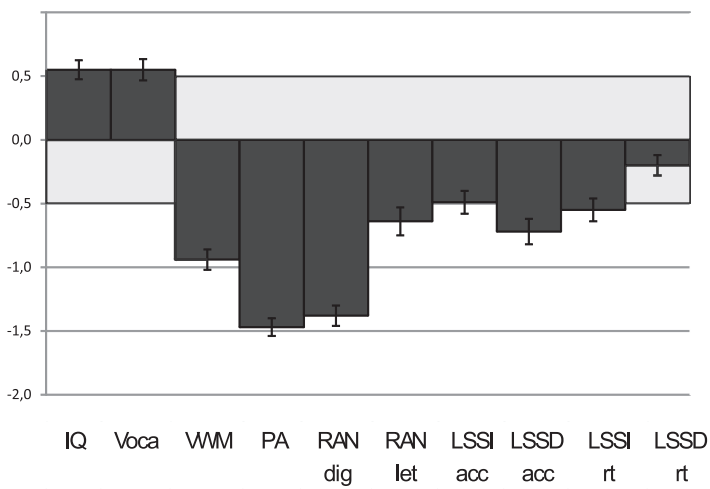

Fig. 2. Visual representation of the cognitive profiles of the poor reader subtypes. Average performance expressed in standardized $z$-scores $(x$-axis) with standard error bars on the general cognitive variables and reading-related vulnerability markers ( $y$-axis) per poor reader type. Voca, vocabulary; VWM, verbal working memory; PA, phonological awareness - phoneme deletion; RAN, rapid naming; dig, digits; let, letters; LSSI, letter-speech sound identification; LSSD, letter-speech sound discrimination; acc, accuracy; RT, response time. For a summary of $z$-scores, standard deviations and post hoc analyses (Bonferroni-corrected) see Table 3. 
Table 4

Mean reading and spelling performance per poor reader type.

\begin{tabular}{|c|c|c|c|c|c|c|c|c|c|c|}
\hline & \multirow{3}{*}{\multicolumn{2}{|c|}{$\begin{array}{l}\text { Type } 1 \\
\text { Read-only } \\
n=86\end{array}$}} & \multirow{3}{*}{\multicolumn{2}{|c|}{$\begin{array}{l}\text { Type } 2 \\
\text { Gen poor } \\
n=76\end{array}$}} & \multirow{3}{*}{\multicolumn{2}{|c|}{$\begin{array}{l}\text { Type } 3 \\
\text { PA-LS } \\
n=79 \\
\end{array}$}} & \multirow{3}{*}{\multicolumn{2}{|c|}{$\begin{array}{l}\text { Type } 4 \\
\text { PA-RAN } \\
n=93\end{array}$}} & \multirow[t]{4}{*}{$F$-value } & \multirow[t]{4}{*}{ Post hoc } \\
\hline & & & & & & & & & & \\
\hline & & & & & & & & & & \\
\hline & $M$ & $S D$ & $M$ & $S D$ & $M$ & $S D$ & $M$ & $S D$ & & \\
\hline Age & 103.15 & 12.31 & 109.01 & 12.91 & 108.11 & 11.34 & 107.43 & 10.83 & $4.02^{*}$ & $1<2=3=4$ \\
\hline \multicolumn{11}{|l|}{ Reading } \\
\hline $3 \mathrm{DM}$ & -1.40 & 0.60 & -1.62 & 0.56 & -1.65 & 0.60 & -1.81 & 0.60 & $8.95^{* *}$ & $1<2=3=4$ \\
\hline OMT & -1.32 & 0.82 & -1.51 & 0.74 & -1.46 & 0.82 & -1.51 & 0.79 & $9.56^{* * *}$ & $1<2=3=4$ \\
\hline Klepel & -1.27 & 0.50 & -1.42 & 0.55 & -1.42 & 0.46 & -1.41 & 0.53 & $12.57^{* *}$ & $1<2=3=4$ \\
\hline \multicolumn{11}{|l|}{ Spelling } \\
\hline $3 \mathrm{DM}$ & -0.47 & 0.82 & -1.40 & 0.81 & -1.13 & 0.82 & -0.98 & 0.93 & $17.47^{* *}$ & $1<2=3=4$ \\
\hline Spel-to-dic & -0.46 & 1.02 & -0.87 & 0.96 & -0.73 & 1.04 & -0.79 & 0.98 & $7.62^{* *}$ & $1<2=3=4$ \\
\hline
\end{tabular}

Read-only, reading-only impaired readers; Gen Poor, general poor readers; PA-LS, PA-LS specific poor readers; PA-RAN, PA-RAN specific poor readers; Spelto-dic, spelling-to-dictation.

Reading fluency in correct items/second, Spelling in number of correct items. Performance on all tasks expressed in standardized $z$-scores.

$* p<0.05$.

** $p<0.01$

Table 5

Proportions on familial and environmental risk factors per poor reader type.

\begin{tabular}{|c|c|c|c|c|c|c|c|c|c|c|}
\hline & \multirow{2}{*}{\multicolumn{2}{|c|}{$\begin{array}{l}\text { Type } 1 \\
\text { Read-only }\end{array}$}} & \multirow{2}{*}{\multicolumn{2}{|c|}{$\begin{array}{l}\text { Type } 2 \\
\text { Gen poor }\end{array}$}} & \multirow{2}{*}{\multicolumn{2}{|c|}{$\begin{array}{l}\text { Type } 3 \\
\text { PA-LS }\end{array}$}} & \multirow{2}{*}{\multicolumn{2}{|c|}{$\begin{array}{l}\text { Type } 4 \\
\text { PA-RAN }\end{array}$}} & \multirow[t]{3}{*}{$\chi^{2}$} & \multirow[t]{3}{*}{ Comparison } \\
\hline & & & & & & & & & & \\
\hline & $\%$ & $n$ & $\%$ & $n$ & $\%$ & $n$ & $\%$ & $n$ & & \\
\hline Fam Risk & 19 & 16 of 86 & 24 & 18 of 76 & 20 & 16 of 79 & 63 & 54 of 86 & $52.15^{*}$ & $4>2=3=1$ \\
\hline Par SES & 33 & 28 of 86 & 67 & 51 of 76 & 68 & 54 of 79 & 24 & 21 of 86 & $51.59^{*}$ & $2=3>1=4$ \\
\hline Soc SES & 32 & 25 of 78 & 50 & 33 of 66 & 51 & 36 of 70 & 31 & 26 of 85 & $11.74^{*}$ & $2=3>1=4$ \\
\hline School read & 69 & 50 of 73 & 44 & 31 of 71 & 43 & 26 of 61 & 46 & 24 of 52 & $12.67^{*}$ & $1>2=3=4$ \\
\hline
\end{tabular}

Read-only, reading-only impaired readers; Gen Poor, general poor readers; PA-LS, PA-LS specific poor readers; PA-RAN, PA-RAN specific poor readers; Fam Risk, familial risk for dyslexia; Par SES, parental education SES; Soc SES, social neighborhood status; School read, lower school reading performance level; $\chi^{2}$, chi-square test.

* $p<0.01$.

was based on at least one first-degree family member (sibling or parent) suffering from severe childhood literacy difficulties since official dyslexia diagnoses in parental generations are rare in the Netherlands. We did however have information on proportions of impaired first-degree family members who also had an official dyslexia diagnosis and results showed that official diagnosis of either a sibling or parent was more common in PA-RAN poor readers (50\%) compared to the other poor reader types (19\% in type 1,22\% in type 2 and 31\% in type 3). The general poor and PA-LS specific poor readers showed a significantly higher proportion of children with a poor SES based on parental education than the PA-RAN specific and reading-only impaired poor readers, respective proportions were 67\% (type 2), 68\% (type 3), 24\% (type 4) and 33\% (type 1). Similarly, the general poor and PA-LS specific poor readers showed a significantly higher proportion of children with poor social SES based on neighborhood social status score than the PA-RAN specific and reading-only impaired poor readers, respective proportions were 50\% (type 2), 51\% (type 3), 31\% (type 4) and 32\% (type 1 ). The information of SES was missing for in total 35 children (i.e., between $9 \%$ and $13 \%$ per type). The reading-only impaired reader subtype (type 1) showed a significantly higher proportion of children (69\%) attending school with a lower school reading performance level (i.e., a high proportion of poor readers) than the other three subtypes that did not differ (44\% in type 2, 43\% in type 3 and $46 \%$ in type 4 ). Please note, proportion could only be calculated based on participants recruited via schools since school information of children from the dyslexia institutes was missing (i.e., 13 from reading-only impaired, 41 from PA-RAN, 18 from PA-LS and 5 from general poor).

Finally, gender (proportions of girls) and co-morbidity characteristics (i.e., arithmetic difficulties and ADHD) were compared. There was no difference in gender between the poor reader types, showing similar proportions of girls: readingonly impaired reader type (44\%, 38 of 86 ), general poor (51\%, 39 of 76), PA-LS specific ( $43 \%, 34$ of 79 ) and PA-RAN specific ( $47 \%, 44$ of 93$), \chi^{2}(3)=1.30 p=0.73$. Proportions of parental concern on arithmetic difficulties was very small and similar across poor reader types: reading-only impaired reader type (6\%, 5 of 86), general poor (7\%, 5 of 76), PA-LS (8\%, 6 of 79 ) and PA-RAN $(7 \%, 6$ of 86$), \chi^{2}(3)=0.23, p=0.97$. The number of children with a formal ADHD diagnosis was very small and did not differ between types: reading-only impaired reader type (0\%), general poor ( $1 \%, 1$ of 76$)$, PA-LS specific (0\%) and PA-RAN specific ( $4 \%, 3$ of 86$), \chi^{2}(3)=5.70, p=0.13$. 


\section{Discussion}

The present data-driven classification approach identified profiles of cognitive deficits in a large sample of grade 2-4 poor readers and subsequently explored the relation between these cognitive profiles and familial history risk and environmental risk factors contributing to reading failure. Four stable subtypes of reading disability emerged from cluster analyses: the reading-only impaired readers (type 1 ), the general poor readers (type 2), the PA-LS specific poor readers (type 3 ) and the PARAN specific poor readers (type 4). They are based on the following four cognitive, candidate risk factors known to mark vulnerability for reading failure: phonological awareness (PA), rapid naming (RAN), letter-speech sound processing (LS), and verbal working memory (VWM), next to general cognitive abilities (i.e., IQ and vocabulary). The reading-only impaired readers (type 1) show no impairments on any clustering variables despite their reading failure. The other three identified types of poor reading (general poor readers, PA-LS specific, PA-RAN specific) share a PA deficit and reveal a specific and unique deficit pattern across the other cognitive clustering variables. The general poor readers (type 2) demonstrate a general impaired performance on all vulnerability markers in accordance with their inferior general cognitive skills. The PALS specific poor readers (type 3) exhibit a specific deficit in LS in addition to the shared PA deficit, with average RAN, low average IQ and average vocabulary. The PA-RAN poor readers (type 4) reveal impaired PA and RAN, low average LS in combination with average IQ and vocabulary. The reading-only impaired type 1 poor readers are significantly younger ( 5 months) than the other three poor reader types and attend schools classified as lower reading performance schools (i.e., $69 \%$ of children attend one of the schools out of the 13 participating schools ranked as lower reading performance schools compared to approximately $45 \%$ in the other three subtypes of poor reading). The general poor readers (type 2) and the PA-LS specific poor readers (type 3) are characterized by overall poorer SES based on poorer parental education (i.e., two-third of poor readers are characterized by a socio-economic status level within the low to low-average categories, which was around one-third in the PA-RAN specific and reading-only impaired poor readers) and poorer neighborhood social SES (i.e., half of the general poor and PA-LS specific poor readers show a poor social status score of $1 S D$ below the norm as compared to onethird in the PA-RAN specific and reading-only impaired poor readers). On the other hand, the poor readers in the PA-RAN specific profile (type 4) are at a significant higher familial risk for dyslexia (i.e., two-third of the PA-RAN specific poor readers have one or more first-degree family member(s) with severe reading difficulties, which was only around one-fifth of poor readers in the other three profiles). Finally, the four subtypes show no clinically significant co-morbidity (i.e., occurrence of ADHD and arithmetic problems was very low and non-discriminative).

The present results confirmed the existence of heterogeneity at the level of cognitive deficits in reading disability (Menghini et al., 2010; Pennington et al., 2012; van Bergen, van der Leij et al., 2014) and support the view that it is possible to identify distinct poor reading subtypes within the heterogeneous group that constitutes reading disabled children (e.g., Heim \& Grande, 2012; Heim et al., 2008; King et al., 2007; Morris et al., 1998; Pacheco et al., 2014). The reading-only impaired type 1 poor readers without underlying general cognitive deficits seems puzzling. These poor readers score within the normal standardized range on all reading-related and general cognitive abilities despite their reading difficulties. A closer look reveals that this subtype has significantly less impaired reading fluency skills than the other three subtypes with cognitive deficits underlying their reading difficulties, and also is the only poor reader type scoring within average range on spelling. Results show that these poor readers are significantly younger than in the other three subtypes, making it possible that specific underlying cognitive deficits are not yet revealed. Although younger, type 1 poor readers however did not attend a significantly lower school grade, indicating that their non-specific reading deficit is not due to not yet being exposed to higher grade reading instruction. These poor readers did however attend schools with a lower reading performance level based on high proportions of poor readers at that school (i.e., two-thirds of this subtype compared to $44 \%$ in type $2,43 \%$ in type 3 and $46 \%$ in type 4, although the proportion of the latter group should be interpreted with care since PA-RAN poor readers were tested at their dyslexia institute and school information was missing in $40 \%$ of this subtype). As for the comparison between the other three subtypes, although we acknowledge that factors beyond the scope of the current study may explain why type 1 children showed poor reading skill in the absence of other deficits and adequate intellectual ability, the school reading performance level may indicate that a possible explanation might lie in inadequate reading instruction at school, which seems more easily counterattacked by more adequate or intensive instruction.

The other three identified poor reader profiles did show a unique and distinct cognitive deficit pattern underlying their reading problems. Firstly, all three subtypes of poor reading share a PA deficit which is in line with findings from other classification attempts (e.g., Fletcher et al., 1994; Morris et al., 1998) and corroborates the phonological-core variable difference model (Stanovich \& Siegel, 1994). This model suggests that poor readers with lower intellectual capacities and educational opportunities (i.e., IQ-reading congruent type) are more likely to show a more generally impaired profile across general and reading-related abilities (i.e., type 2 in the current study) compared to those disabled readers with relatively higher IQs (i.e., IQ-reading discrepant type) with a more specific reading-related deficit (i.e., type 3 and 4 ). Although this model predicts that the phonological deficit of the IQ-reading discrepant poor readers would be more severe, the current findings indicated that the PA deficit in the general poor readers was worse consistent with their overall cognitive deficit profile, Nevertheless, results are in compliance with various reports that show that all poor reading types are well predicted by PA deficits, irrespective of IQ level (e.g., Fletcher et al., 1994; Stanovich, 1991; Stanovich \& Siegel, 1994). In line with this are the results of recent neuroimaging studies confirming that brain activation patterns during phonological processing of print are similar for low-IQ and high-IQ poor readers (Simos et al., 2013; Tanaka et al., 2011). The present result moreover supports the generally accepted reciprocal correlation between phonological awareness and reading (Blomert \& Willems, 
2010; Castles \& Coltheart, 2004; Wagner \& Torgesen, 1987). While IQ scores seem to differ between our emerging cognitive subtypes of poor reading, our results also indicate that it is important in for the identification and remediation of reading disability to look at the overall general and reading-related cognitive profile of children. This finding corroborates previous accounts made against solely basing classification of reading failure on the more traditionally used IQ-discrepancy definition (Stanovich \& Siegel, 1994; Stuebing et al., 2002).

Next to a shared PA deficit, a differential expression of underlying cognitive deficits across other domains was found in these three poor reader subtypes. The generally impaired poor readers (type 2) reveal a rather poor and non-differentiated cognitive profile across all reading-related risk markers and general cognitive skills (being the only profile with impaired verbal working memory, for similar VWM results in general poor readers see for instance Daal \& Leij, 1999; De Jong, 1998). In contrast, the two specifically impaired poor reader profiles each show a unique reading-related deficit, in addition to the common PA deficit. More specifically, the PA-LS specific poor readers show poor letter-speech sound accuracy processing skills, next to a PA deficit. The PA-RAN specific type demonstrates additional impaired rapid naming skills, suggesting a relation between PA and RAN. Overall, we can conclude that these results do not directly fit into a double-deficit framework proposed by Wolf and Bowers (1999). One would expect a PA-only deficit type, a RAN-only deficit type and a type showing deficits in both domains (for classification results pointing in this direction see King et al., 2007; Morris et al., 1998). The double-deficit hypothesis expects the two deficits to be independent and additive, resulting in a more severe form of dyslexia in the double-deficit subtype as compared to the single deficit subtypes. However, the present results reveal no 'pure' RANonly core deficit type, independent of PA problems (corroborating the findings of other behavioral studies directly investigating the main assumptions of the double-deficit hypothesis; Badian, 1997; Bowers \& Ishaik, 2003; Pennington, Cardoso-Martins, Green, \& Lefly, 2001; Vaessen et al., 2009; Vukovic \& Siegel, 2006; Wagner \& Torgesen, 1987). Pennington et al. (2001) for example only found 1 child within their sample of 71 dyslexic readers with a RAN specific impairment. Similarly, Vaessen et al. (2009) indicated that only 5\% of their sample showed RAN difficulties without affected PA skills, leaving them to conclude that RAN is merely a different (speeded) manifestation of the same underlying deficit in the phonological domain, with the unique addition that RAN problems might reflect the inefficient and slower cross-modal matching of visual-orthographic codes (also see Araújo et al., 2011). The present data cannot contribute directly to the discussion on whether RAN reflects cross-modal ability uniquely and independent of phonological processing. Nevertheless our results demonstrate that RAN is a useful cognitive clustering variable, able to differentiate between distinct cognitive profiles within the heterogeneous sample of poor readers, where traditional PA tasks alone cannot.

The finding of an LS specific deficit, next to a shared PA deficit, in our PA-LS specific poor readers (type 3 ) is in line with the few previous studies focusing on this vulnerability marker. Learning letter-sound pairs is found to be an immediate problem for a substantial part of kindergarten children at-risk for reading failure, already before reading instruction (Blomert \& Willems, 2010). Moreover, older poor readers are slower in LS mapping skills than normally developing peers up to the end of primary school (Blomert \& Vaessen, 2009). In fact, while normal readers improve this skill up to grade 6, poor readers show a premature halting after grade 3. This extended weakness or even inability to efficiently map letters-sound pairs in dyslexic children is further confirmed by recent brain imaging studies (Blau et al., 2010; Froyen et al., 2011) and even indicated far beyond primary school in dyslexic adults (Blau et al., 2009; for a summery see Blomert, 2011). Although LS processing is a seemingly important vulnerability marker of poor reading it has, to our knowledge, never been included in previous poor reading classification studies (Fletcher et al., 1994; King et al., 2007; Morris et al., 1998; Pacheco et al., 2014). At least, the present result of a distinct poor reader type with LS problems indicates the importance of including such a differentiating measure in future classification research, especially given the information it can provide for subsequent diagnostic and intervention efforts.

Finding distinct cognitive patterns of deficits in three of the four emerging poor reader profiles suggests a possible difference in underlying etiology through which these three subtypes arrive at their similar poor reading and spelling levels. Our results are in line with previous findings of a primarily genetic poor reader type and an environmentally influenced impaired type (Shaywitz \& Shaywitz, 2005). The general poor readers (type 2) and the PA-LS specific poor readers (type 3 ) are characterized by environmental risk factors. Both subtypes of poor reading show significantly poorer socio-economic status (SES) on two measures generally agreed to cover the three most influential components of SES (i.e., the cultural component of parental education, the social component of labor market position and the economical component of family income; Israel, Beaulieu, \& Hartless, 2001). More specific, around two-thirds of the children in type 2 and 3 come from families with a low to low-average parental education (compared to one-third in the PA-RAN and reading-only impaired poor readers). In accordance, they also reveal a poorer neighborhood social status composite score based on average family education, income and occupation status of the child's area of residence (i.e., half of the children scored $1 S D$ below the norm as compared to one-third of the children in the reading-only impaired type and PA-RAN specific profiles). The PA-RAN specific poor readers (type 4) on the other hand exhibit a stronger familial predisposition to the reading failure they experienced: more than twothirds of children have one or more first-degree family members with dyslexia, whereas only one-fifth show a familial risk in the other three types. Although only genetic testing (e.g., twin study designs) can detangle how much variation in a trait is related to genes or environmental factors and, family history of dyslexia is not a pure genetic trait (Pennington \& Olson, 2008; Plomin et al., 1994; Rutter \& Silberg, 2002), being at familial risk is one of the strongest predictive factors of the disorder (Thompson et al., 2015). It is possible that parents with higher SES (based on parental education or higher neighborhood scores) are more aware of possible reading difficulties in their children, over-reporting family history of dyslexia on our parental reports. Results however showed that parents with average to above average education level 
showed similar proportions of at-risk indications (30\%) to parents lower educational level $(36 \%), \chi^{2}=1.17, p=0.28$. Families with an average to high social neighborhood status score also showed comparable proportions of at-risk indications (33\%) compared to families with a lower score (30\%), $\chi^{2}=0.51, p=0.47$. Similarly, parent reports on family history for dyslexia may also be higher in parents from children already referred to a specialized dyslexia institute (sample 2) compared to parents from school children with poor reading skills (sample 1). Results nonetheless showed no difference in at-risk indications between the samples with $30 \%$ at-risk in sample 1 and $39 \%$ at-risk in sample $2, \chi^{2}=1.88, p=0.17$. Taken together, these results seem to support the validity of parental report of family risk of reading failure.

The PA-RAN subtype with increased familial risk for dyslexia also shows significantly higher IQ than the other subtypes influenced more by environmental risk factors. Specifically, the IQ scores of type 4 are approximately $1 S D$ higher than for the PA-LS type 3 poor readers and up to 1.4 SD higher than for the general type 2 poor readers. Finding two types of etiologies, one predominantly influenced by familial risk and characterized by high IQs discrepant to their poor reading profile (i.e., type 4 ) and one primarily environmentally influenced with lower to poor intellectual capabilities (type 2 and 3 ), is well in line with previous recent genetic behavioral results (Castles et al., 1999; Friend, DeFries, \& Olson, 2008; Knopik et al., 2002; Rack \& Olson, 1993; Wadsworth et al., 2000, 2010) and neuroimaging results (Shaywitz \& Shaywitz, 2005). Finding support for the existence of these two possible etiologies for childhood reading could still mean that the same familial risk factors are operative in both etiologies, but that the PA-RAN specific type with high IQs is a more homogeneous environmental subtype and this in turn results in this profile showing a higher impact of familial risk for dyslexia (also see Wadsworth et al., 2000, 2010 for similar results). Thus, these findings do not suggest that different familial risk factors are influencing different types of reading disability as a function of IQ but the proportion of variance accounted for by a familial predisposition may vary since a differential environmental impact might be at play. It is not only known that there is a significantly higher heritability of reading deficits in children with higher IQs (Wadsworth et al., 2000), it is also shown that heritability of dyslexia increases linearly with high levels of parental education (Friend et al., 2008). Consistently, our PA-RAN children at increased familial risk for dyslexia, characterized by higher IQs, also showed a more favorable socio-economic background (based on parental education and income). Although it is still unknown which proximal environmental factors mediate such a geneenvironment interaction (Peterson \& Pennington, 2012), possible candidates include language and (pre)literacy environments provided to children by their parents at home. The PA-RAN children at increased risk for dyslexia who come from families with higher parental education might thus enjoy a more supportive home literacy environment. A recent genetic study even suggested that children with increased genetic predispositions evoke more cognitively stimulating experiences from their environments (Tucker-Drob \& Harden, 2012). Interestingly, previous studies also reveal that, in addition to PA, difficulties with RAN (the deficit specific to type 4) are found to be more related to genetic risk (e.g., Gayan \& Olson, 2001; Petrill, Deater-Deckard, Thompson, DeThorne, \& Schatschneider, 2006; Samuelsson et al., 2005), while letter name and sound knowledge problems (the deficit specific to type 3) is mostly influenced by shared home/preschool environmental factors and only to a small degree by genetic influences (e.g., Byrne et al., 2006, 2013; Samuelsson et al., 2005). It is thus conceivable that a more enriching home environment support might have ameliorated presence of LS weakness in our PA-RAN subtype, but not in our PA-LS poor readers from less favorable SES backgrounds. Reading and reading-related deficits due to a substantial larger genetic influence may in turn require more intensive remediation efforts though (Wadsworth et al., 2010).

Taken together, the present clustering approach was able to confirm the existence of distinct and homogeneous subtypes of poor reading substantially characterized by either familial risk factors or environmental risk factors, purely based on cognitive vulnerability markers commonly used for the diagnostics of dyslexia. And although IQ has fallen out of favor for sole diagnosis of dyslexia based on discrepancy or cut-off criteria (Stanovich \& Siegel, 1994; Stuebing et al., 2002), the way IQ forms distinct patterns with these cognitive vulnerability markers as well as family history of dyslexia, seems informative and supports the idea that IQ can provide more information on the cause of the reading deficit experienced by the child (Friend et al., 2008; Wadsworth et al., 2000, 2010) as well as have a valuable attribution for exclusion purposes in diagnostic processes (Coltheart \& Jackson, 1998; Rack \& Olson, 1993). It may be noted that these clustering results are supported by the use of a data-driven, bottom-up approach, making no a priori assumptions on either the number or theoretical nature of subtypes, beyond the included clustering variables. A possible limitation of the study might be that these included cognitive vulnerability markers are based on one cognitive task only. A recommended improvement would be to include more than on measure per marker to increase stability of each cognitive, clustering construct. Moreover, we do not exclude the existence of additional, emerging subtypes if more than the currently employed classification measures were included. Finally, given that the relative severity and impact of cognitive deficits are commonly found to vary as a function of reading expertise and age (Landerl \& Wimmer, 2008; Vaessen \& Blomert, 2010), we recommend utilizing periodic reevaluation to determine whether the obtained latent clustering of deficits continues to be appropriate.

The present classification study provides evidence for distinct and coherent cognitive deficit patterns of poor reading. Despite a shared deficit in phonological awareness, a variable expression of other underlying cognitive deficits was found across several reading-related vulnerability markers and general cognitive domains, which differentiated between a poor reader type with a predominantly familial predisposition and two other poor readers that where characterized most by poor environmental factors. While letter-speech sound difficulties where characteristic in one of the environmentally influenced profiles (the other being the general poor reader type), a rapid automatized naming deficit was specific for the poor reader type at elevated familial risk for dyslexia. The present results indicate that it is useful to include information on familial and environmental risk when identifying subtypes of poor reading and subsequently define tailored intervention efforts. 
Moreover, it might also be a promising way forward for genetic testing studies to not just look at the reading impaired group as a whole as is usually done, but look at the heterogeneous group of poor readers with finer clustering resolution, focusing in on underlying cognitive subtypes. From a methodological point of view, we could demonstrate that using large sample size and the external validation of the different subtypes in combination with a multi-start re-sampling method ensured the optimal number and stability of clusters representing the present data.

\section{Acknowledgements}

We thank the schools, children, parents and assistants for their enthusiastic participation and contribution. We are grateful to the Regional Institute of Dyslexia (RID) for their assistance in participant recruitment. The authors also wish to thank Dr. Arie van der Lugt and the four reviewers for their useful comments on the manuscript. This research was partly supported by a grant (608/001/2005) of the Dutch National Board of Health Care Insurance to our co-author Prof. Dr. Leo Blomert, who passed away on November 25, 2012.

\section{References}

Adams, M. J. (1990). Beginning to read: Thinking and learning about print. Cambridge, MA: The MIT Press.

Araújo, S., Faísca, L., Bramão, I., Inácio, F., Petersson, K. M., \& Reis, A. (2011). Object naming in dyslexic children: More than a phonological deficit. The Journal of General Psychology, 138(3), 215-228. http://dx.doi.org/10.1002/dys.433

Badian, N. A. (1997). Dyslexia and the double deficit hypothesis. Annals of Dyslexia, 47, 69-87. http://dx.doi.org/10.1007/s11881-997-0021-y

Bartelet, D., Ansari, D., Vaessen, A., \& Blomert, L. (2014). Cognitive subtypes of mathematics learning difficulties in primary education. Research in Developmental Disabilities, 35(3), 657-670. http://dx.doi.org/10.1016/j.ridd.2013.12.010

Beneventi, H., Tønnessen, F. E., Ersland, L., \& Hugdahl, K. (2010). Working memory deficit in dyslexia: Behavioral and fMRI evidence. International Journal of Neuroscience, 120(1), 51-59. http://dx.doi.org/10.3109/00207450903275129

Berninger, V. W., Abbott, R. D., Billingsley, F., \& Nagy, W. (2001). Processes underlying timing and fluency: Efficiency, automaticity coordination and morphological awareness. In M. Wolf (Ed.), Dyslexia, fluency and the brain (pp. 383-414). Timonium, MD: York Press.

Berninger, V. W., Abbott, R. D., Thomson, J., Wagner, R., Swanson, H. L., Wijsman, E. M., et al. (2006). Modeling phonological core deficits within a working memory architecture in children and adults with developmental dyslexia. Scientific Studies of Reading, 10(2), 165-198. http://dx.doi.org/10.1207/ s1532799xssr1002_3

Bishop, D. V. M. (2006). Developmental cognitive genetics: How psychology can inform genetics and vice versa. The Quarterly Journal of Experimental Psychology, 59(7), 1153-1168. http://dx.doi.org/10.1080/17470210500489372

Bishop, D. V. M. (2008). Specific language impairment, dyslexia, and autism: Using genetics to unravel their relationship. Understanding Developmental Language Disorders: From Theory to Practice, 67-78.

Blau, V., Reitler, J., Van Atteveldt, N., Gerretsen, P., Seitz, J., Goebel, R., et al. (2010). Deviant processing of letters and speech sounds as proximate cause of reading failure: An fMRI study of dyslexic children. Brain, 133(3), 868-879. http://dx.doi.org/10.1093/brain/awp308

Blau, V., Van Atteveldt, N., Ekkebus, M., Goebel, R., \& Blomert, L. (2009). Reduced neural integration of letters and speech sounds links phonological and reading deficits in adult dyslexia. Current Biology, 19(6), 503-508. http://dx.doi.org/10.1016/j.cub.2009.01.065

Bleichrodt, N., Drenth, P. D., Zaal, J. N., \& Resing, W. C. M. (1988). RAKIT: Revisie Amsterdamse Kinder Intelligentie Test [revision Amsterdam Children Intelligence Test]. Lisse: Swets \& Zeitlinger.

Blomert, L. (2005). Dyslexie in Nederland - Theorie praktijk en beleid [Dyslexia in The Netherlands - Theory, practice and policy]. Amsterdam: Nieuwezijds Publishers.

Blomert, L. (2011). The neural signature of orthographic-phonological binding in successful and failing reading development. Neuroimage, 57(3), 695-703. http://dx.doi.org/10.1016/j.neuroimage.2010.11.003

Blomert, L., \& Vaessen, A. (2009). 3DM: Cognitieve analyse van lezen en spellen [3DM: Cognitive analysis of reading and spelling]. Amsterdam: Boom test publishers BV.

Blomert, L., \& Willems, G. (2010). Is there a causal link from a phonological awareness deficit to reading failure in children at familial risk for dyslexia? Dyslexia: An International Journal of Research and Practice, 16, 300-317. http://dx.doi.org/10.1002/dys.405

Boets, B., Wouters, J., Van Wieringen, A., \& Ghesquiere, P. (2007). Auditory processing, speech perception and phonological ability in pre-school children at high-risk for dyslexia: A longitudinal study of the auditory temporal processing theory. Neuropsychologia, 45(8), 1608-1620. http://dx.doi.org/10.1016/ j.neuropsychologia.2007.01.009

Bowers, P. G., \& Ishaik, G. (2003). RAN's contribution to understanding reading disabilities. In S. Graham, H. Swanson, \& K. R. Lee Harris (Eds.), Handbook of learning disabilities (pp. 140-157). New York, NY: Guilford Press.

Bowers, P. G., \& Wolf, M. (1993). Theoretical links among naming speed, precise timing mechanisms and orthographic skill in dyslexia. Reading and Writing, 5(1), 69-85. http://dx.doi.org/10.1007/BF01026919

Brus, B. T., \& Voeten, M. J. M. (1973). Een-minuuttest vorm A en B. Nijmegen: Berkhout.

Buly, M. R., \& Valencia, S. W. (2002). Below the bar: Profiles of students who fail state reading assessments. Educational Evaluation and Policy Analysis, 24(3), 219-239. http://dx.doi.org/10.2307/3594166

Byrne, B., Olson, R. K., Samuelsson, S., Wadsworth, S. J., Corley, R., DeFries, J. C., et al. (2006). Genetic and environmental influences on early literacy. Journal of Research in Reading, 29(1), 33-49. http://dx.doi.org/10.1111/j.1467-9817.2006.00291.x

Byrne, B., Wadsworth, S. J., Boehme, K., Talk, A. C., Coventry, W. L., Olson, R. K., et al. (2013). Multivariate genetic analysis of learning and early reading development. Scientific Studies of Reading, 17(3), 224-242. http://dx.doi.org/10.1080/10888438.2011.654298

Caravolas, M., Lervåg, A., Defior, S., Málková, G. S., \& Hulme, C. (2013). Different patterns, but equivalent predictors, of growth in reading in consistent and inconsistent orthographies. Psychological Science. http://dx.doi.org/10.1177/0956797612473122 0956797612473122

Caravolas, M., Lervåg, A., Mousikou, P., Efrim, C., Litavsky, M., Onochie-Quintanilla, E., et al. (2012). Common patterns of prediction of literacy development in different alphabetic orthographies. Psychological Science, 23(6), 678-686. http://dx.doi.org/10.1177/0956797611434536. 0956797611434536 [pii]

Carroll, J. M., Mundy, I. R., \& Cunningham, A. J. (2014). The roles of family history of dyslexia, language, speech production and phonological processing in predicting literacy progress. Developmental Science, 17(5), 727-742. http://dx.doi.org/10.1111/desc.12153

Carroll, J. M., \& Snowling, M. J. (2004). Language and phonological skills in children at high risk of reading difficulties. Journal of Child Psychology and Psychiatry, 45(3), 631-640. http://dx.doi.org/10.1111/j.1469-7610.2004.00252.x

Castles, A., \& Coltheart, M. (2004). Is there a causal link from phonological awareness to success in learning to read? Cognition, 91(1), 77-111. http:// dx.doi.org/10.1016/S0010-0277(03)00164-1

Castles, A., Datta, H., Gayan, J., \& Olson, R. K. (1999). Varieties of developmental reading disorder: Genetic and environmental influences. Journal of Experimental Child Psychology, 72(2), 73-94. http://dx.doi.org/10.1006/jecp.1998.2482

Castles, A., Wilson, K., \& Coltheart, M. (2011). Early orthographic influences on phonemic awareness tasks: Evidence from a preschool training study. Journal of Experimental Child Psychology, 108(1), 203-210. http://dx.doi.org/10.1016/j.jecp.2010.07.006 
Clarke, P., Hulme, C., \& Snowling, M. J. (2005). Individual differences in RAN and reading: A response timing analysis. Journal of Research in Reading, 28(2), 73-86. http://dx.doi.org/10.1111/j.1467-9817.2005.00255.x

Coltheart, M., \& Jackson, N. E. (1998). Defining dyslexia. Child and Adolescent Mental Health, 3(1), 12-16. http://dx.doi.org/10.1111/1475-3588.00202

Compton, D. L., DeFries, J. C., \& Olson, R. K. (2001). Are RAN- and phonological awareness-deficits additive in children with reading disabilities? Dyslexia, 7(3), 125-149. http://dx.doi.org/10.1002/dys.198

Daal, V., \& Leij, A. (1999). Developmental dyslexia: Related to specific or general deficits? Annals of Dyslexia, 49(1), 71-104. http://dx.doi.org/10.1007/ s11881-999-0020-2

Davis, C. J., Gayán, J., Knopik, V. S., Smith, S. D., Cardon, L. R., Pennington, B. F., et al. (2001). Etiology of reading difficulties and rapid naming: The Colorado Twin Study of reading disability. Behavior Genetics, 31(6), 625-635. http://dx.doi.org/10.1023/a:1013305730430

de Bruyn, E., van der Steenen, G., \& van Haasen, P. (1986). Wechsler intelligence scale for children-revided (WISC-R). In Nederlandstalige uitgave en verantwoording. Lisse: Swets \& Zeitlinger.

De Jong, P. F. (1998). Working memory deficits of reading disabled children. Journal of Experimental Child Psychology, 70(2), 75-96. http://dx.doi.org/ 10.1006/jecp.1998.2451

de Jong, P. F., \& van der Leij, A. (1999). Specific contributions of phonological abilities to early reading acquisition: Results from a Dutch latent variable longitudinal study. Journal of Educational Psychology, 91(3), 450-476. http://dx.doi.org/10.1037/0022-0663.91.3.450

Elbro, C., Borstrøm, I., \& Petersen, D. K. (1998). Predicting dyslexia from kindergarten. The importance of distinctness of phonological representations of lexical items. Reading Research Quarterly, 33(1), 36-60. http://dx.doi.org/10.1598/RRQ.33.1.3

Felton, R. H., \& Brown, I. S. (1990). Phonological processes as predictors of specific reading skills in children at risk for reading failure. Reading and Writing: An Interdisciplinary Journal, 2(1), 39-59. http://dx.doi.org/10.1007/BF00383373

Field, A. (2005). Discovering statistics using SPSS. Sussex: Sage Publications.

Fletcher, J. M., Shaywitz, S. E., Shankweiler, D. P., Katz, L., Liberman, I. Y., Stuebing, K. K., et al. (1994). Cognitive profiles of reading disability: comparisons of discrepancy and low achievement definitions. Journal of Educational Psychology, 86(1), 6-23. http://dx.doi.org/10.1037/0022-0663.86.1.6

Friend, A., DeFries, J. C., \& Olson, R. K. (2008). Parental education moderates genetic influences on reading disability. Psychological Science, 19(11), 11241130. http://dx.doi.org/10.1111/j.1467-9280.2008.02213.x

Froyen, D., Bonte, M., Van Atteveldt, N., \& Blomert, L. (2009). The long road to automation: Neurocognitive development of letter-speech sound processing. Journal of Cognitive Neuroscience, 21, 567-580. http://dx.doi.org/10.1162/jocn.2009.21061

Froyen, D., Van Atteveldt, N., Bonte, M., \& Blomert, L. (2008). Cross-modal enhancement of the MMN to speech-sounds indicates early and automatic integration of letters and speech-sounds. Neuroscience Letters, 430(1), 23-28. http://dx.doi.org/10.1016/j.neulet.2007.10.014

Froyen, D., Willems, G., \& Blomert, L. (2011). Evidence for a specific cross-modal association deficit in dyslexia: An electrophysiological study of letterspeech sound processing. Developmental Science, 14(4), 635-648. http://dx.doi.org/10.1111/j.1467-7687.2010.01007.x

Gayan, J., \& Olson, R. K. (2001). Genetic and environmental influences on orthographic and phonological skills in children with reading disabilities. Developmental Neuropsychology, 20(2), 483-507. http://dx.doi.org/10.1207/s15326942dn2002_3

Geelhoed, J., \& Reitsma, P. (1999). Pi-dictee. Lisse: Swets \& Zeitlinger.

Georgiou, G. K., Das, J. P., \& Hayward, D. V. (2008). Comparing the contribution of two tests of working memory to reading in relation to phonological awareness and rapid naming speed. Journal of Research in Reading, 31(3), 302-318. http://dx.doi.org/10.1111/j.1467-9817.2008.00373.x

Goswami, U., \& Bryant, P. (1990). Phonological skills and learning to read. Hove, UK: Lawrence Erlbaum.

Gough, P. B., \& Tunmer, W. E. (1986). Decoding, reading, and reading disability. Remedial and Special Education, 7, 6-10. http://dx.doi.org/10.1177/ 074193258600700104

Grigorenko, E. L. (2001). Developmental dyslexia: An update on genes, brains, and environments. Journal of Child Psychology and Psychiatry, 42(1), 91-125. http://dx.doi.org/10.1111/1469-7610.00704

Heim, S., \& Grande, M. (2012). Fingerprints of developmental dyslexia. Trends in Neuroscience and Education, 1(1), 10-14. http://dx.doi.org/10.1016/ j.tine.2012.09.001

Heim, S., Tschierse, J., Amunts, K., Wilms, M., Vossel, S., Willmes, K., et al. (2008). Cognitive subtypes of dyslexia. Acta Neurobiologiae Experimentalis, 68(1), 73-82.

Israel, G. D., Beaulieu, L. J., \& Hartless, G. (2001). The influence of family and community social capital on educational achievement. Rural Sociology, 66(1), 43-68. http://dx.doi.org/10.1111/j.1549-0831.2001.tb00054.x

Jeffries, S., \& Everatt, J. (2004). Working memory: Its role in dyslexia and other specific learning difficulties. Dyslexia, 10(3), 196-214. http://dx.doi.org/ $10.1002 /$ dys. 278

Jiménez, J. E., Siegel, L., O'Shanahan, I., \& Ford, L. (2009). The relative roles of IQ and cognitive processes in reading disability. Educational Psychology, 29(1), 27-43. http://dx.doi.org/10.1080/01443410802459226

Jolliffe, I. T. (1986). Principle component analysis. New York: Springer-Verlag.

Kibby, M. Y., Marks, W., Morgan, S., \& Long, C. J. (2004). Specific impairment in developmental reading disabilities: A working memory approach. Journal of Learning Disabilities, 37(4), 349-363. http://dx.doi.org/10.1177/00222194040370040601

King, W. M., Giess, S. A., \& Lombardino, L. J. (2007). Subtyping of children with developmental dyslexia via bootstrap aggregated clustering and the gap statistic: Comparison with the double-deficit hypothesis. International Journal of Language \& Communication Disorders, 42(1), 77-95. http://dx.doi.org/ $10.1080 / 13682820600806680$

Knol, F. (2012). Statusontwikkeling van wijken in Nederland 1998-2010. Publication by Sociaal Cultureel Planbureau.

Knopik, V., Smith, S., Cardon, L., Pennington, B. F., Gayan, J., Olson, R. K., et al. (2002). Differential genetic etiology of reading component processes as a function of IQ. Behavior Genetics, 32(3), 181-198. http://dx.doi.org/10.1023/A:1016069012111

Landerl, K., \& Wimmer, H. (2008). Development of word reading fluency and spelling in a consistent orthography: An 8-year follow-up. Journal of Educational Psychology, 100, 150-161. http://dx.doi.org/10.1037/0022-0663.100.1.150

Lyon, G. R. (1989). IQ is irrelevant to the definition of learning disabilities: A position in search of logic and data. Journal of Learning Disabilities, $22(8), 504$.

Lyon, G. R. (1995). Toward a definition of dyslexia. Annals of Dyslexia, 45(1), 1-27. http://dx.doi.org/10.1007/BF02648210

Lyon, G. R., Shaywitz, S. E., \& Shaywitz, B. A. (2003). A definition of dyslexia. Annals of Dyslexia, 53, 1-14. http://dx.doi.org/10.1007/s11881-003-0001-9

MacCallum, R. C., Widaman, K. F., Zhang, S., \& Hong, S. (1999). Sample size in factor analysis. Psychological Methods, 4(1), 84.

MATLAB (2001). Version 6. Natick, MA: The Mathworks Inc.

McBride-Chang, C., \& Manis, F. R. (1996). Structural invariance in the associations of naming speed, phonological awareness, and verbal reasoning in good and poor readers: A test of the double deficit hypothesis. Reading and Writing: An Interdisciplinary Journal, 8(4), 323-339. http://dx.doi.org/10.1007/ BF00395112

McCallum, R. S., Bell, S. M., Wood, M. S., Below, J. L., Choate, S. M., \& McCane, S. J. (2006). What is the role of working memory in reading relative to the big three processing variables (Orthography Phonology, and Rapid Naming)? Journal of Psychoeducational Assessment, 24(3), 243-259. http://dx.doi.org/ $10.1177 / 0734282906287938$

Menghini, D., Finzi, A., Benassi, M., Bolzani, R., Facoetti, A., Giovagnoli, S., et al. (2010). Different underlying neurocognitive deficits in developmental dyslexia: A comparative study. Neuropsychologia, 48(4), 863-872.

Moll, K., Loff, A., \& Snowling, M. J. (2013). Cognitive endophenotypes of dyslexia. Scientific Studies of Reading, 17(6), 385-397. http://dx.doi.org/10.1080/ 10888438.2012 .736439

Morais, J., Cary, L., Alegria, J., \& Bertelson, P. (1979). Does awareness of speech as a sequence of phones arise spontaneously? Cognition, 7, 323-331. http:// dx.doi.org/10.1016/0010-0277(79)90020-9

Morris, R. D., Stuebing, K. K., Fletcher, J. M., Shaywitz, S. E., Lyon, G. R., Shankweiler, D. P., et al. (1998). Subtypes of reading disability: Variability around a phonological core. Journal of Educational Psychology, 90(3), 347-373. http://dx.doi.org/10.1037/0022-0663.90.3.347 
Pacheco, A., Reis, A., Araújo, S., Inácio, F., Petersson, K., \& Faísca, L. (2014). Dyslexia heterogeneity: Cognitive profiling of Portuguese children with dyslexia. Reading and Writing, 27(9), 1529-1545. http://dx.doi.org/10.1007/s11145-014-9504-5

Pennington, B. F., Cardoso-Martins, C., Green, P. A., \& Lefly, D. L. (2001). Comparing the phonological and double deficit hypotheses for developmental dyslexia. Reading and Writing: An Interdisciplinary Journal, 14, 707-755. http://dx.doi.org/10.1023/A:1012239018038

Pennington, B. F., \& Lefly, D. L. (2001). Early reading development in children at family risk for dyslexia. Child Development, 72(3), 816-833. http:// dx.doi.org/10.1111/1467-8624.00317

Pennington, B. F., \& Olson, R. K. (2008). Genetics of dyslexia. In The Science of Reading: A Handbook (pp. 453-472) http://dx.doi.org/10.1002/ 9780470757642.ch24

Pennington, B. F., Santerre-Lemmon, L., Rosenberg, J., MacDonald, B., Boada, R., Friend, A., et al. (2012). Individual prediction of dyslexia by single versus multiple deficit models. Journal of Abnormal Psychology, 121(1), 212.

Perfetti, C. A., Beck, I., Bell, L. C., \& Hughes, C. (1987). Phonemic knowledge and learning to read are reciprocal: A longitudinal study of first grade children. Merill-Palmer Quarterly, 33(3), 283-319.

Peterson, R. L., \& Pennington, B. F. (2012). Developmental dyslexia. Lancet, 379(9830), 1997-2007. http://dx.doi.org/10.1016/S0140-6736(12)60198-6. S0140-6736(12)60198-6 [pii]

Petrill, S. A., Deater-Deckard, K., Thompson, L. A., DeThorne, L. S., \& Schatschneider, C. (2006). Genetic and environmental effects of serial naming and phonological awareness on early reading outcomes. Journal of Educational Psychology, 98(1), 112-121. http://dx.doi.org/10.1037/0022-0663.98.1.112

Pierce, M. E., Katzir, T., Wolf, M., \& Noam, G. G. (2007). Clusters of second and third grade dysfluent urban readers. Reading and Writing, 20(9), 885-907. http://dx.doi.org/10.1007/s11145-007-9058-X

Plomin, R., Reiss, D., Hetherington, E. M., \& Howe, G. W. (1994). Nature and nurture: Genetic contributions to measures of the family environment. Developmental Psychology, 30(1), 32. http://dx.doi.org/10.1037/0012-1649.30.1.32

Puolakanaho, A., Ahonen, T., Aro, M., Eklund, K., Leppänen, P., Poikkeus, A., et al. (2008). Developmental links of very early phonological and language skills to second grade reading outcomes: Strong to accuracy but only minor to fluency. Journal of Learning Disabilities, 41(4), 353-370. http://dx.doi.org/ $10.1177 / 0022219407311747$

Rack, J. P., \& Olson, R. K. (1993). Phonological deficits, IQ, and individual differences in reading disability: genetic and environmental influences. Developmental Review, 13(3), 269-278. http://dx.doi.org/10.1006/drev.1993.1013

Ramus, F. (2003). Developmental dyslexia: Specific phonolical deficit or general sensorimotor dysfunction? Current Opinion in Neurobiology, 13, 212-218. http://dx.doi.org/10.1016/S0959-4388(03)00035-7

Ramus, F., Rosen, S., Dakin, S. C., Day, B. L., Castellote, J. M., White, S., et al. (2003). Theories of developmental dyslexia: Insights from a multiple case study of dyslexic adults. Brain: A Journal of Neurology, 126(4), 841-865. http://dx.doi.org/10.1093/brain/awg076

Rourke, B. P. (1985). Neuropsychology of learning disabilities: Essentials of subtype analysis.

Rutter, M., \& Silberg, J. (2002). Gene-environment interplay in relation to emotional and behavioral disturbance. Annual Review of Psychology, 53(1), 463-490. http://dx.doi.org/10.1146/annurev.psych.53.100901.135223

Rutter, M., \& Yule, W. (1975). The concept of specific reading retardation. Journal of Child Psychology and Psychiatry, 16, 181-197. http://dx.doi.org/10.1111/ j.1469-7610.1975.tb01269.x

Samuelsson, S., Byrne, B., Quain, P., Wadsworth, S., Corley, R., DeFries, J. C., et al. (2005). Environmental and genetic influences on prereading skills in Australia, Scandinavia, and the United States. Journal of Educational Psychology, 97(4), 705-722. http://dx.doi.org/10.1037/0022-0663.97.4.705

Sarstedt, M., \& Mooi, E. (2014). A concise guide to market research: The process, data and methods using IBM SPSS statistics. Springer.

Satz, P., \& Morris, R. (1981). Learning disability subtypes: A review. In F. J. Pirozzolo \& M. C. Wittrock (Eds.), Neuropsychological and cognitive processes in reading (pp. 109-141). New York: Academic Press.

Scarborough, H. S. (1990). Very early language deficits in dyslexic children. Child Development, 61, 1728-1743. http://dx.doi.org/10.2307/1130834

Scholte, E. M., \& van der Ploeg, J. D. (2005). Handleiding ADHD-vragenlijst (AVL)Houten: Bohn Stafleu Van Loghum.

Seymour, P., Aro, M., \& Erskine, J. (2003). Foundation literacy acquisition in European orthographies. British Journal of Psychology, 94(2), 143-174. http:// dx.doi.org/10.1348/000712603321661859

Shaywitz, S. E., \& Shaywitz, B. A. (2005). Dyslexia (specific reading disability). Biological Psychiatry, 57(11), 1301-1309. http://dx.doi.org/10.1016/ j.biopsych.2005.01.043

Simos, P. G., Rezaie, R., Papanicolaou, A. C., \& Fletcher, J. M. (2013). Does IQ affect the functional brain network involved in pseudoword reading in students with reading disability? A magnetoencephalography study. Frontiers in Human Neuroscience, 7, 932. http://dx.doi.org/10.3389/fnhum.2013.00932

Snowling, M. J. (2000). Dyslexia. Oxford: Blackwell Publishers.

Snowling, M. J. (2008). Specific disorders and broader phenotypes: The case of dyslexia. The Quarterly Journal of Experimental Psychology, 61(1), 142-156. http://dx.doi.org/10.1080/17470210701508830

Snowling, M. J. (2012). Changing concepts of dyslexia: Nature, treatment and comorbidity. Journal of Child Psychology and Psychiatry, 53(9), e1-e3. http:// dx.doi.org/10.1111/j.1469-7610.2009.02197.x

Snowling, M. J., Gallagher, A., \& Frith, U. (2003). Family risk of dyslexia is continuous: Individual differences in the precursors of reading skill. Child Development, 74(2), 358-373. http://dx.doi.org/10.1111/1467-8624.7402003

Snowling, M. J., \& Hulme, C. (2012). Annual Research Review: The nature and classification of reading disorders - A commentary on proposals for DSM-5. Journal of Child Psychology and Psychiatry, 53(5), 593-607. http://dx.doi.org/10.1111/j.1469-7610.2011.02495.x

Stanovich, K. E. (1988). Explaining the differences between dyslexic and the garden-variety poor reader. The phonological-core variable-difference model. Journal of Learning Disabilities, 21, 590-612. http://dx.doi.org/10.1177/002221948802101003

Stanovich, K. E. (1991). Discrepancy definitions of reading disability: Has intelligence led us astray? Reading Research Quarterly, 26, 7-29.

Stanovich, K. E., \& Siegel, L. S. (1994). Phenotypic performance profile of children with reading disabilities: A regression-based test of the phonologicalcore-variable-difference model. Journal of Educational Psychology, 86, 24-53. http://dx.doi.org/10.1037//0022-0663.86.1.24

Steinley, D. (2006). K-means clustering: A half-century synthesis. British Journal of Mathematical and Statistical Psychology, 59(1), 1-34. http://dx.doi.org/ $10.1348 / 000711005 \times 48266$

Stuebing, K. K., Barth, A. E., Molfese, P. J., Weiss, B., \& Fletcher, J. M. (2009). IQ is not strongly related to response to reading instruction: A meta-analytic interpretation. Exceptional Children, 76(1), 31-51.

Stuebing, K. K., Fletcher, J. M., LeDoux, J. M., Lyon, G. R., Shaywitz, S. E., \& Shaywitz, B. A. (2002). Validity of IQ-discrepancy classifications of reading disabilities: A meta-analysis. American Educational Research Journal, 39(2), 469-518. http://dx.doi.org/10.3102/00028312039002469

Sunseth, K., \& Bowers, P. G. (2002). Rapid naming and phonemic awareness: Contributions to reading, spelling, and orthographic knowledge. Scientific Studies of Reading, 6, 401-429. http://dx.doi.org/10.1207/S1532799XSSR0604_05

Tanaka, H., Black, J. M., Hulme, C., Stanley, L. M., Kesler, S. R., Whitfield-Gabrieli, S., et al. (2011). The brain basis of the phonological deficit in dyslexia is independent of IQ. Psychological Science, 22(11), 1442-1451. http://dx.doi.org/10.1177/0956797611419521. 0956797611419521 [pii]

Thompson, P. A., Hulme, C., Nash, H. M., Gooch, D., Hayiou-Thomas, E., \& Snowling, M. J. (2015). Developmental dyslexia: Predicting individual risk. Journal of Child Psychology and Psychiatry and Allied Disciplines, 56(9), 976-987. http://dx.doi.org/10.1111/jcpp.12412

Tijms, J. (2004). Verbal memory and phonological processing in dyslexia. Journal of Research in Reading, 27, 300-310. http://dx.doi.org/10.1111/j.1467-9817. 2004.00233.x

Torgesen, J. K., Wagner, R. K., \& Rashotte, C. A. (1994). Longitudinal studies of phonological processing and reading. Journal of Learning Disabilities, 27, 276-291. http://dx.doi.org/10.1177/002221949402700503

Tucker-Drob, E. M., \& Harden, K. P. (2012). Early childhood cognitive development and parental cognitive stimulation: Evidence for reciprocal geneenvironment transactions. Developmental Science, 15(2), 250-259. http://dx.doi.org/10.1111/j.1467-7687.2011.01121.x 
Vaessen, A., \& Blomert, L. (2010). Long term cognitive dynamics of fluent reading development. Journal of Experimental Child Psychology, 105, $213-231$. http://dx.doi.org/10.1016/j.jecp.2009.11.005

Vaessen, A., Gerretsen, P., \& Blomert, L. (2009). Naming problems do not reflect a second, independent core deficit in dyslexia: 'Double deficits' explored. Journal of Experimental Child Psychology, 103, 202-221. http://dx.doi.org/10.1016/j.jecp.2008.12.004

van Bergen, E., de Jong, P. F., Maassen, B., \& van der Leij, A. (2014). The effect of parents' literacy skills and children's preliteracy skills on the risk of dyslexia. Journal of Abnormal Child Psychology, 42(7), 1187-1200. http://dx.doi.org/10.1007/s10802-014-9858-9

van Bergen, E., van der Leij, A., \& de Jong, P. F. (2014). The intergenerational multiple deficit model and the case of dyslexia. Frontiers in Human Neuroscience, 8, 346. http://dx.doi.org/10.3389/fnhum.2014.00346

Van Bon, W. H. J. (1986). Raven's coloured progressive matrices. Nederlandse normen en enige andere uitkomsten van onderzoek. Lisse, NL: Swets \& Zeitlinger.

van den Bos, K. P., Lutje Spelberg, H. C., Scheepstra, A. J. M., \& de Vries, J. R. (1994). Handleiding van de Klepel. Nijmegen: Berkhout.

Vellutino, F. R., Fletcher, J. M., Snowling, M. J., \& Scanlon, D. M. (2004). Specific reading disability (dyslexia): What have we learned in the past four decades? Journal of Child Psychology and Psychiatry, 45(1), 2-40. http://dx.doi.org/10.1046/j.0021-9630.2003.00305.x

Vukovic, R. K., \& Siegel, L. S. (2006). The double-deficit hypothesis: A comprehensive analysis of the evidence. Journal of Learning Disabilities, 39(1), 25-47. http://dx.doi.org/10.1177/00222194060390010401

Wadsworth, S. J., Olson, R. K., \& DeFries, J. C. (2010). Differential genetic etiology of reading difficulties as a function of IQ: An update. Behavior Genetics, 40(6), 751-758. http://dx.doi.org/10.1007/s10519-010-9349-X

Wadsworth, S. J., Olson, R. K., Pennington, B. F., \& DeFries, J. C. (2000). Differential genetic etiology of reading disability as a function of IQ. Journal of Learning Disabilities, 33(2), 192-199. http://dx.doi.org/10.1177/002221940003300207

Wagner, R. K., \& Torgesen, J. K. (1987). The nature of phonological processing and its causal role in the acquisition of reading skills. Psychological Bulletin, 101, 192-212. http://dx.doi.org/10.1037/0033-2909.101.2.192

Williams, J., \& O'Donovan, M. C. (2006). The genetics of developmental dyslexia. European Journal of Human Genetics, 14(6), 681-689. http://dx.doi.org/ 10.1038/sj.ejhg. 5201575

Wolf, M. (1997). A provisional integrative account of phonological and naming-speed deficits in dyslexia: Implications for diagnosis and intervention. In B. A. Blachman \& A. Benita (Eds.), Foundations of reading acquisition and dyslexia: Implications for early intervention (pp. 67-92). Mahwah, NY: Lawrence Erlbaum Associates.

Wolf, M., \& Bowers, P. G. (1999). The double-deficit hypothesis for the developmental dyslexias. Journal of Educational Psychology, 91(3), 415-438. http:// dx.doi.org/10.1037/0022-0663.91.3.415

Zaric, G., Fraga Gonzalez, G., Tijms, J., van der Molen, M. W., Blomert, L., \& Bonte, M. (2015). Crossmodal deficit in dyslexic children: Practice affects the neural timing of letter-speech sound integration. Frontiers in Human Neuroscience, 9, 369. http://dx.doi.org/10.3389/fnhum.2015.00369

Zoubrinetzky, R., Bielle, F., \& Valdois, S. (2014). New insights on developmental dyslexia subtypes: Heterogeneity of mixed reading profiles. PLOS ONE, 9(6), e99337. http://dx.doi.org/10.1371/journal.pone.0099337 